Review Article

\title{
Currently Available Biomarkers and Strategies for the Validation of Novel Candidates for Neurochemical Dementia Diagnostics in Alzheimer's Disease and Mild Cognitive Impairment
}

\author{
Piotr Lewczuk \\ Department of Psychiatry and Psychotherapy, Universitätsklinikum Erlangen and Friedrich-Alexander Universität Erlangen-Nürnberg, \\ Erlangen, Germany \\ Correspondence should be addressed to Piotr Lewczuk; piotr.lewczuk@uk-erlangen.de
}

Received 12 January 2014; Revised 15 May 2014; Accepted 29 May 2014; Published 18 June 2014

Academic Editor: Richard C. Dodel

Copyright (C) 2014 Piotr Lewczuk. This is an open access article distributed under the Creative Commons Attribution License, which permits unrestricted use, distribution, and reproduction in any medium, provided the original work is properly cited.

\begin{abstract}
The number of people afflicted with Alzheimer's disease (AD) and other types of dementing conditions has grown exponentially in the last decades. This review focuses on the diagnostic role of the classic cerebrospinal fluid (CSF) biomarkers of neurochemical dementia diagnostics (NDD) and critically discusses potential strategies for the development and validation of novel potential candidates. In some countries, NDD is already established as a routine diagnostic tool, used for the evaluation of patients with cognitive impairments. On the other hand, preanalytical and technical issues, partly discussed in this paper, prevent NDD from the general acceptance worldwide. Currently, two groups of biomarkers in the CSF are considered in NDD: amyloid $\beta$ (A $\beta$ ) peptides and Tau proteins, including the hyperphosphorylated forms of the latter (pTau). The analyses of these two groups of biomarkers can reveal pathologic alterations as early as twenty years before the onset of clinical symptoms. In mild cognitive impairment (MCI), NDD can reliably predict which individuals are at risk of converting to $\mathrm{AD}$. The roles of biomarkers of amyloid $\beta$ deposition in the brain tissue (including the CSF concentration of $\mathrm{A} \beta 42$ ) and biomarkers of neurodegeneration (including the CSF concentrations of Tau/pTau proteins) are reflected in the currently proposed diagnostic criteria for AD and MCI.
\end{abstract}

\section{Introduction: Alzheimer's Disease versus Alzheimer's Dementia}

The number of people with Alzheimer's disease (AD) and other types of dementing conditions has drastically increased over the last decades. Approximately 14 million people in Europe and the USA are currently afflicted by AD, including more than $40 \%$ of the population over the age of 85 years $[1,2]$. In the USA, AD is the seventh leading cause of death, and the annual costs associated with this disease in 2010 were $\$ 172$ billion in the USA and over $\$ 600$ billion worldwide [3]. Moreover, dementing conditions cause a tremendous burden for the relatives of the afflicted patients; in 2010, nearly 15 million family members and other unpaid caregivers provided an estimated 17 billion hours of care for people with $\mathrm{AD}$ and other dementias [2].
The discovery of drugs that could treat this devastating condition would undoubtedly represent a breakthrough in medicine. However, to achieve this goal, it is important to have diagnostic tools that are capable of correctly discriminating patients and preferentially in the earliest preclinical stages. It is also important to precisely define what is being discussed; that is, it is important to realize that the terms of Alzheimer's disease (abbreviated as $\mathrm{AD}$ in this paper) and Alzheimer's dementia must not be carelessly interchanged. Whereas "dementia" is a syndrome, "Alzheimer's disease" is a more or less defined diagnostic entity. Dementia is not pathognomonic for $\mathrm{AD}$, nor is $\mathrm{AD}$ characterized solely by dementia, at least not initially. This distinction is particularly important in the context of early diagnosis because the process of Alzheimer's disease requires decades to cause clinically observable and diagnosable symptoms, one of which is 
dementia. The phase of the disease between the moment at which the pathobiochemical processes begin and the moment at which the clinical diagnosis of AD is established according to any of the available criteria is defined as "preclinical" or "presymptomatic" $\mathrm{AD}$ and can persist for twenty years. This long time window in which this disorder of the central nervous system (CNS) is silent is far from specific to $\mathrm{AD}$; other CNS diseases that are present for extended periods without visible symptoms include Parkinson's disease and multiple sclerosis.

The pathologic changes of AD begin in the medial temporal lobe and subsequently progress to areas associated with the neocortex $[4,5]$. These alterations begin decades before the onset of clinical symptoms [6-8], and correspondingly, $\mathrm{AD}$ is considered to progress according to the following three stages: (a) a presymptomatic stage, (b) a prodromal stage that includes mild symptoms (e.g., alterations in episodic memory), and (c) a symptomatic stage that includes dementia [9]. The mild cognitive impairment (MCI) stage precedes the cognitive dysfunctions of dementia in AD. While as many as $10-20 \%$ of subjects with MCI progress to AD yearly [10], other causes of MCI include normal aging, cerebrovascular disease, depression, excessive alcohol/drug use, and neurodegeneration unrelated to AD [11].

The diagnosis of early dementia due to AD based solely on clinical symptoms remains difficult, particularly in the prodromal phase $[9,12]$. This difficulty is reflected in the generally low accuracy of clinical AD diagnostic methods that do not include biomarker information; reasonable sensitivities of approximately $71-88 \%$ have been observed, but the specificities are much lower (44-71\% depending on the specific histopathologic diagnostic criteria employed [13]).

Intensive efforts have been expended in the last twenty years to develop disease-modifying drugs that can halt the progression of $\mathrm{AD}$. Once these drugs are (hopefully) approved, diagnostic tools will be required to recognize the subgroups of patients in early $\mathrm{AD}$ who could benefit from treatment with these drugs. Moreover, there is a growing body of evidence suggesting that biomarkers are needed for the identification of patients for inclusion in registration trials of these disease-modifying drugs.

Two neuropathologic features are commonly found in the brains of patients with $\mathrm{AD}$ : extracellular senile plaques, which are composed of amyloid $\beta(\mathrm{A} \beta)$ peptides, and intracellular neurofibrillary tangles that contain hyperphosphorylated Tau proteins [14]. Therefore, it is unsurprising that these two groups of molecules are the best-established biomarkers of this disease.

\section{Neurochemical Dementia Diagnostics}

Neurochemical dementia diagnostics (NDD) is a term introduced by our group some eight years ago [15] to describe biomarkers routinely used to support the diagnosis of $\mathrm{AD}$ and other neurodegenerative disorders. It has been used since then, although strictly spoken it is not fully correct: dementia cannot be, precisely spoken, diagnosed with laboratory tools; it is a syndrome that can be evaluated with neuropsychological tests. Therefore, the term NDD must be used only when these limitations are kept in mind.

2.1. Cerebrospinal Fluid (CSF). All currently accepted neurochemical biomarkers of $\mathrm{AD}$ are analyzed in the cerebrospinal fluid (CSF); thus, we will briefly discuss the physiology and pathophysiology of the CSF before addressing the biomarkers of $\mathrm{AD}$ in more detail in the following sections.

Under normal conditions, CSF is a colorless and transparent fluid that is produced as an ultrafiltrate of the blood in the choroid plexus of the ventricles of the brain. In adult humans, the daily CSF production rate is approximately $500 \mathrm{~mL}$, whereas the total volume of the CSF at a given moment is approximately $150 \mathrm{~mL}$, which indicates that the entire volume of the CSF is turned over three times daily. CSF flows from the lateral ventricles through the foramina of Monro to the third ventricle and then through the cerebral aqueduct (the mesencephalic duct) to the fourth ventricle; from there, the CSF enters the cisterna magna through the single median and double lateral apertures (Magendie and Luschka, resp.). Here, the CSF is divided into a portion that bathes the brain occupying the subarachnoid space and another portion, also in the subarachnoid space, that flows down along the spinal cord. Eventually, the CSF is reabsorbed into the blood via arachnoid granulations. It is important to realize that the CSF does not "circulate"; that is, a given portion of CSF never returns to its place of origin in the ventricles of the brain. This detail has important consequences in terms of differences in the composition of the CSF in different anatomical regions. Due to the processes of passive diffusion and active transport, the ventricular CSF is enriched in brain-derived proteins and poor in blood-derived proteins, whereas CSF collected from the lumbar region (via lumbar puncture (LP)) contains lower amounts of brain-derived proteins due to passive diffusion from the CSF into the blood during the flow of the CSF through the subarachnoid space, but this CSF is enriched in blood-derived proteins that passively diffuse from the blood into the CSF as it flows along the spinal cord. For example, albumin is an exclusively blood-derived protein, and the rostrocaudal concentration gradient (between the ventricles and the lumbar region) of albumin is approximately $1: 2.5$ [16]. These physiologic differences in the composition of the CSF result in differences in laboratory norms for CSF samples that depend on the anatomical site at which the CSF is collected.

The CSF plays a crucial role in the diagnosis of diseases of the nervous system; for example, a detailed discussion of CSF findings related to inflammatory disorders of the central nervous system can be found in Reiber and Peter [17]. Nevertheless, brief discussions of the blood-CSF barrier and the functions of the immune system in the CNS are also relevant here because both dysfunctions of the bloodCSF barrier and immune reactions in the CNS that can be observed in the CSF are occasionally observed in AD and other neurodegenerative disorders $[18,19]$.

The blood-CSF barrier is not the same as the blood-brain barrier, and these two concepts must not be interchanged. Whereas the blood-brain barrier is anatomically located in 
the walls of the brain capillaries, which, due to their tight junctions, limit the passage of molecules from one side of the vesicle wall to the other, the blood-CSF barrier is a physiologic mechanism (and not an anatomical structure) that passively influences the diffusion of molecules (e.g., proteins) from the blood into the CSF along the bulk flow pathway of the CSF. Moreover, it has been postulated that the function of the blood-CSF barrier depends, perhaps exclusively, on the CSF flow rate [16]; this statement implies that pathological alterations and structures, particularly those located close to the CSF flow pathways, strongly alter the function of the blood-CSF barrier. Perhaps two of the most spectacular examples of such pathologies are prolapsed discs and spinal cord tumors, both of which limit the CSF flow rate and cause corresponding alterations in the function of the blood-CSF barrier.

The ratio of the rates of diffusion of two given bloodderived proteins with different molecular sizes (i.e., different molecular masses) follows a hyperbolic function [16], and this finding has formed a solid framework for modern CSF protein analyses and clinical neurochemistry. Such ratios are typically diagnostically utilized for comparisons of the concentration quotients $(\mathrm{Q})$ of two blood-derived proteins. One of these proteins is typically albumin $\left(\mathrm{Q}_{\mathrm{Alb}}\right)$, which is used as a biomarker of blood-CSF barrier function. If the second protein analyzed is, for example, immunoglobulin $\mathrm{G}\left(\mathrm{Q}_{\mathrm{IgG}}\right)$, the application of the hyperbolic formula allows for estimation if the fraction of the IgG found in the CSF comes from intrathecal production by the $\mathrm{B}$ cells localized in the brain tissue and not only from passive diffusion from the blood. Analysis of the IgG released within the CNS (i.e., intrathecally) enables correct interpretation of the IgG concentration of a CSF sample, particularly in cases of dysfunction of the blood-CSF barrier. Even a large IgG concentration in the CSF does not indicate intrathecal synthesis if a correspondingly large blood-CSF barrier dysfunction (i.e., increased $\mathrm{Q}_{\mathrm{Alb}}$ ) is present; in such situations, the large IgG concentration is merely a consequence of the passive diffusion of IgG from the blood through the blood-CSF barrier. In everyday laboratory practice, graphical representations in the forms of "Reibergrams," which are easy to follow, are extremely helpful for the analyses of $\operatorname{IgG}$, IgA, and $\operatorname{IgM}$.

2.2. Lumbar Puncture (LP). Lumbar puncture, the routine procedure for the collection of CSF for diagnostic purposes, is much less invasive than generally believed. Nevertheless, to some extent LP is invasive, which limits its acceptance and, thus, that of CSF analysis, particularly in the prodromal phase of $\mathrm{AD}$. However, it is important to note that certain imaging techniques (such as PET) can also be considered invasive extent because they involve the intravenous administration of a radioactive tracer. Severe complications associated with LP are rare, and the study on 1,089 consecutive patients (aged 23-89 years) who underwent lumbar puncture as a part of the routine diagnostic evaluation revealed postlumbar headache in $2.6 \%$ of the patients [20], which is comparable to the risk of headache after amyloid PET [20, 21]. In another study, $2.5 \%$ of patients reported "severe headache" [22]; however,
Popp et al. reported that $9 \%$ of the patients developed a postlumbar puncture syndrome of mild or middle intensity [23]. Nevertheless, the acceptance of LP and the use of CSF biomarkers vary significantly across countries, and further measures are certainly required to overcome the obstacles of $\mathrm{LP}$ before its use in the diagnosis of $\mathrm{AD}$ becomes a routine.

2.3. Amyloid Precursor Protein and Its Metabolites. Amyloid plaques are mainly composed of the peptides derived from the enzymatic cutting of $\beta$-amyloid precursor protein (APP) [24]. In humans, this transmembrane protein is encoded by a gene on chromosome 21, and alternative splicing results in at least eight forms of this protein. The form known as APP 695 (i.e., the form that consists of 695 amino acid residues) is expressed predominantly in the brain [25]. The physiological role of APP is not currently clear; however, it is postulated to be involved in cell-to-cell and matrix interactions. The enzymatic processing of APP by $\beta$-secretase(s) followed by $\gamma$-secretase(s) leads to the release of several forms of $\mathrm{A} \beta$ peptides. Interestingly, the discovery of $\mathrm{A} \beta$ peptides that end at different $\mathrm{C}$-termini led to the conclusion that different $\gamma$-secretase activities may exist [26, 27]; however, an alternative mechanism involving the dependency of the cleavage site on the length of the intramembrane APP domain has been postulated [28]. APP can also be processed by $\alpha$-secretase, and this processing results in the release of soluble APP $\alpha$ but not $\mathrm{A} \beta$ peptides from the so-called "nonamyloidogenic pathway."

Interestingly, in addition to the full-length $\mathrm{A} \beta$ peptides, that is, those with aspartic acid at the $\mathrm{N}$-terminal (position "1"), the N-terminally shortened forms seem to play a role in the pathophysiology of $\mathrm{AD}$. Truncated fragments (A $\beta 11-$ 42 and $A \beta 17-42$ ) are also found in amyloid plaques and in the preamyloid lesions of Down syndrome, which is used as a model system for the study of early-onset AD. Little is known about the structures and activities of these smaller peptides, although they may be the primary pathological agents of $\mathrm{AD}$ and Down syndrome. Using atomic force microscopy, channel conductance measurements, and calcium imaging, Jang et al. showed that the nonamyloidogenic $A \beta 9-42$ and $A \beta 17-$ 42 peptides form ion channels with loosely attached subunits and elicit single-channel conductances [29]. Although the $\mathrm{N}$ terminally shortened forms of $\mathrm{A} \beta$ are definitely interesting from a pathophysiologic point of view, their diagnostic value as potential biomarkers of $\mathrm{AD}$ currently remains unclear.

In vitro, $\mathrm{A} \beta$ peptides can be metabolized by many enzymes; in vivo animal studies have focused mainly on two groups of enzymes, insulin-degrading enzyme (IDE) and neprilysin. The role of IDE in the degradation of $A \beta$ peptides seems to be particularly interesting from the pathophysiologic point of view because it links two degenerative diseases, $\mathrm{AD}$ and diabetes mellitus type 2 (DM2). Indeed, $\mathrm{DM} 2$ is one of the risk factors for the development of $\mathrm{AD}$ [30]. Increases in the insulin levels of human subjects increase the concentrations of $A \beta$ in the CSF [31-33], which may be due to the fact that IDE degrades insulin more efficiently than do $\mathrm{A} \beta$ peptides. If this explanation is correct, increases in insulin levels could perhaps redistribute the available 
IDE activity away from its function as an $\mathrm{A} \beta$-degrading enzyme. Such redistribution would be sensible from the homeostatic point of view because acute increases in insulin concentrations are more dangerous than temporary increases in the concentrations of $\mathrm{A} \beta$ peptides.

Several studies, including these from our group, have reported decreased CSF concentrations of $A \beta$ peptides with $\mathrm{C}$-termini that end at $42(\mathrm{~A} \beta 42)([34,35]$, and reviews: $[4,36])$ and unchanged total levels of $\mathrm{A} \beta$ peptides in $\mathrm{AD}$ patients [37]. The mechanisms that lead to the decreased concentrations of $\mathrm{A} \beta 42$ in the CSF of $\mathrm{AD}$ patients have not yet been clarified. The accumulation of this peptide in the plaques has been suggested by some investigators; however, this hypothesis cannot explain the finding of a selective decrease in the concentration of $A \beta 42$ in the CSF of a subgroup of patients with Creutzfeldt-Jakob disease (CJD) who did not develop any amyloid plaques [38]. Similarly, decreased levels of $A \beta 42$ in the CSF have been recorded in cases of bacterial meningitis [39], which may cause chronic memory deficits but does not present with $\mathrm{A} \beta$ plaques.

In a recently published paper, Spies et al. [40] systematically and critically reviewed the potential mechanisms that could lead to the decreases in $\mathrm{A} \beta 42$ concentrations in the CSF in AD. One theoretically possible explanation involves a hypothetical decrease in the rate of $\mathrm{A} \beta$ generation. For example, this decrease may be due to decreases in the numbers of the neurons that release $A \beta$ peptides into the brain parenchyma. However, this hypothesis disagrees with the increased load of $A \beta 42$ in the brain tissue [41]. Moreover, in this scenario, in addition to $\mathrm{A} \beta 42$, the CSF concentrations of other isoforms (including the two most abundant $\mathrm{A} \beta$ peptides in the human CSF, $A \beta 40$ and $A \beta 38$ ) should be decreased in $\mathrm{AD}$, which is not the case. A further counterargument is that $\mathrm{A} \beta 42$ concentrations are decreased in familial $\mathrm{AD}$ and Down syndrome, and these diseases are characterized by the genetically driven overproduction of $\mathrm{A} \beta$ peptides [42]. Moreover, because the concentrations of soluble APP are actually increased in the CSF of $\mathrm{AD}$ and MCI-AD patients $[43,44]$ and because the sAPP $\beta$ and $\mathrm{A} \beta$ peptides (including $A \beta 42$ ) are released from the same metabolic pathway, it is difficult to accept that the reduction of $A \beta 42$ concentration is caused by a decrease in its production.

Another potential mechanism leading to the decreased CSF $A \beta 42$ concentration in $A D$ might be an increase in the degradation of $A \beta 42$. However, such an increase in degradation should also affect other $\mathrm{A} \beta$ peptides, particularly $\mathrm{A} \beta 40$ because $\mathrm{A} \beta 40$ and $\mathrm{A} \beta 42$ are largely metabolized by the same enzymes; for example, IDE degrades $A \beta 1-40$ and A $\beta 1-42$ with similar efficiencies [45]. Moreover, increased degradation of $A \beta 42$ should lead to a decrease in the formation of $\mathrm{A} \beta 42$ deposits in the brain parenchyma, which would hamper the formation of plaques. Because this is not the case, one can assume that the increased degradation hypothesis cannot explain the decreased $\mathrm{A} \beta 42$ concentrations observed in $\mathrm{AD}$.

The next potential explanation of the decreased CSF A $\beta 42$ concentrations observed in $\mathrm{AD}$ is that the clearance of $\mathrm{A} \beta 42$ from the brain tissue to the blood across the blood-brain barrier is increased. This mechanism would lead to decreases in the numbers of $\mathrm{A} \beta 42$ molecules in the brain parenchyma, which would indicate that a correspondingly decreased number of $A \beta 42$ molecules could enter the CSF. Indeed, $\mathrm{A} \beta$ peptides are actively transported across the blood-brain barrier by the lipoprotein receptor-related protein. Some investigators have reported increased expression of this transporter in perivascular cells in response to $\mathrm{A} \beta 42$ but not $\mathrm{A} \beta 40$ in vitro; however, the uptake of $\mathrm{A} \beta 42$ by these cells results in their degeneration [46]. In contrast, other studies have found that the expression of lipoprotein receptor-related protein is decreased in $\mathrm{AD}$ and that the mechanisms of the transport of $\mathrm{A} \beta$ from the blood to the brain are upregulated [47]. Moreover, we [48] and other investigators $[49,50]$ have found decreased $\mathrm{A} \beta 42$ concentrations and/or $\mathrm{A} \beta 42 / 40$ ratios in the blood of $\mathrm{AD}$ patients and subjects at risk for $\mathrm{AD}$, which further argues against the notion that the clearance of parenchymal $\mathrm{A} \beta 42$ into the blood is the cause of decrease in A $\beta 42$ concentration in the CSF.

Finally, an interesting but currently unproven hypothesis is that the $\mathrm{A} \beta 42$ concentrations in the CSF of $\mathrm{AD}$ patients only seem to be decreased due to the accumulation of $A \beta 42$ monomers into soluble oligomers that mask the epitopes for the antibodies used in ligand-based analytical methods. Indeed, all currently utilized laboratory methods that measure the concentrations of $\mathrm{A} \beta$ peptides in body fluids are based on antibodies. Thus, the masking of the epitopes by the oligomerization of the $A \beta 42$ monomers, which may be accompanied by alterations in the three-dimensional structures of the $\mathrm{A} \beta 42$ molecules, would make the binding sites inaccessible to capture and/or detection by antibodies. This hypothesis agrees with the increased amounts of $A \beta 42$ in the brain parenchyma of $\mathrm{AD}$ patients and with the fact that $\mathrm{A} \beta 42$ monomers oligomerize in $\mathrm{AD}$. This hypothesis would also explain how an increase in the number of $A \beta 42$ molecules in the CSF could artificially be "seen" as a decrease in their concentration. Indeed, a recently published study provided support for this hypothesis by reporting increased concentrations of $\mathrm{A} \beta$ oligomers in the CSF of $\mathrm{AD}$ patients [51].

Hulstaert et al. [52] reported that the sensitivity and specificity of the use of $\mathrm{A} \beta 1-42$ alone to distinguish $\mathrm{AD}$ patients from elderly controls are $78 \%$ and $81 \%$, respectively, and Galasko et al. reported similar sensitivity and specificity figures of $78 \%$ and $83 \%$, respectively [53]. In our study [34], the utilization of CSF A $\beta 42$ alone resulted in the correct classification of $87 \%$ of the subjects when non-Alzheimer's dementia patients and nondemented individuals were used as a control group that was compared to an $\mathrm{AD}$ patient group.

\subsection{Tau Protein and Its Phosphorylated Forms. Tau proteins} belong to the family of microtubule-associated proteins that are found in neuronal and nonneuronal cells (reviewed in [54]). The human Tau gene is located on the long arm of chromosome 17. Alternative splicing leads to the formation of the following six forms of this protein in the adult human brain: 4R2N, 3R2N, 4R1N, 3R1N, 4R0N, and 3R0N. The lengths of the proteins range from 352 to 441 amino acid residues [55], and longer isoforms that result from 
the expression of exon $4 \mathrm{a}$, which is not transcribed in the CNS, exist in the peripheral nervous system [56]. The physiological role of Tau is still not fully understood. Some studies have suggested that Tau proteins play roles in neuronal microtubule stability, but this interpretation remains controversial. Tau proteins are also involved in promoting microtubule nucleation, growth, and bundling, and it has been hypothesized that the phosphorylation of Tau proteins is an important factor in the regulation of Tau-microtubule interactions (reviewed in [57]). Recently, the group studying the effects of Tau oligomers and filamentous structures in cell models has reported activation of the microglia, with significant morphological alterations as analyzed by immunofluorescence accompanied by the augmentation of nitrites and the proinflammatory cytokine IL-6 [58]. Studies on animal models with mouse that expresses human Tau demonstrated that the process of neurofibrillary tangle formation, rather than tangles themselves, is responsible for synapse and neuron loss; furthermore hyperphosphorylated Tau or oligomeric Tau seems involved in synaptic loss, whereas granular tau oligomers are responsible for neuronal loss [59]. The phosphorylation status of Tau is thought to change during development; the degree of phosphorylation during the fetal phase is relatively high and is followed by a steady decrease with age that likely results from phosphatase activation $[60,61]$. The total Tau protein concentration has been extensively studied as a nonspecific marker of neuronal destruction in neurodegeneration. A meta-analysis by Sunderland et al. [62], which was based on the data from 17 reports on $\mathrm{A} \beta 42$ and 34 reports on CSF Tau in $\mathrm{AD}$, found that all of these studies reported increased CSF total Tau concentrations in AD. Increased total Tau concentrations in the CSF are observed in neuropsychiatric disorders other than AD, for example, CJD and stroke $[63,64]$. Nevertheless, because Tau can likely be used to monitor the efficacies of neuroprotective drugs in AD patients and because CJD and acute stroke are easily distinguishable from $\mathrm{AD}$ clinically, the observations of increases in CSF total Tau concentrations in other neuropsychiatric diseases should not dampen the value of this marker.

Although increases in total Tau CSF concentrations are thought to reflect nonspecific disruptions of nerve cells, the abnormal hyperphosphorylation of Tau is a hallmark of $\mathrm{AD}$ [65] and hyperphosphorylated Tau molecules form neurofibrillary tangles [66]. Tau can be phosphorylated at seventy-nine putative positions, and serine and threonine are the residues that are predominantly phosphorylated. Across the currently available studies, the mean sensitivities and specificities of Tau phosphorylation at different positions vary from 44 to $94 \%$ and 80 to $100 \%$, respectively [67].

We found that the CSF concentrations of pTau181 were significantly increased in a group of AD patients with clinical diagnoses that were neurochemically supported by decreased A $\beta 42$ in the CSF [68]. This form of Tau seems to be particularly interesting because pTau181 remains unchanged while total Tau is increased after acute stroke [63]; these findings may suggest that pTau181 is not solely a marker of simple neuronal loss. Similarly, Vanmechelen et al. [69] reported a significant increase in the level pTau181 in the CSF of $\mathrm{AD}$ patients compared to all other groups studied (i.e., patients with frontotemporal degeneration, dementia with Lewy bodies (DLB), PD, multiple system atrophy, and progressive supranuclear palsy) with the exception of the corticobasal degeneration. Also Parnetti et al. confirmed that pTau181 is useful as a biomarker for distinguishing $\mathrm{AD}$ from DLB [70]. Regarding other phosphorylation sites, in an international multicenter project, Itoh et al. reported a significant overall increase of pTau199 in patients with $\mathrm{AD}$ compared to all other non-AD groups. In this study, both the sensitivity and the specificity of CSF pTaul99 in the discrimination of $\mathrm{AD}$ from other studied diseases were $85 \%$ at a cutoff level of $1.05 \mathrm{fmol} / \mathrm{mL}$ [71]. Tau phosphorylated at threonine 231 (pTau231) seems to be helpful in the differentiation of $\mathrm{AD}$ from other relevant diseases, that is, frontotemporal dementia, vascular dementia, and DLB (reviewed in [67]). A follow-up study revealed increases in pTau231 CSF concentrations at the onset of the disease that were followed by decreases in the concentrations of pTau231 but not total Tau in a group of untreated AD patients, which suggests a possible role for this form in tracking the natural course of the disease [72]. Interestingly, Tau protein that was phosphorylated at both the threonine 231 and serine 235 positions was found to be increased in patients with MCI who developed $\mathrm{AD}$ within the follow-up period [73]. In this study, the group of patients at risk for developing AD could be distinguished from those who complained of having memory impairment but did not have objective memory loss based on the simultaneous evaluation of total Tau and phosphorylated Tau.

2.5. Combination of Biomarkers and Interpretation-Supporting Algorithms. The matter of whether the amyloid $\beta$ and the Tau/pTau pathways are two independent pathophysiologic processes in $\mathrm{AD}$ or if they influence (or even trigger) each other remains unresolved. On the one hand, the amyloid plaques and neurofibrillary tangles in $\mathrm{AD}$ brains are separated spatially and temporally. On the other hand, a growing body of evidence supports the hypothesis that the accumulation of amyloid $\beta$ in the brain tissue promotes the phosphorylation of Tau molecules. For example, the overproduction of endogenous $\mathrm{A} \beta$ peptides (in cell culture models of mouse neuroblastoma cells transfected with the Swedish mutant APP) upregulates the activity of GSK-3 $\beta$, which is one of the kinases responsible for the phosphorylation of Tau molecules [74]. Grueninger et al. reported enhancement of the phosphorylation of the Tau molecule (at serine 422) due to the accumulation of amyloid $\beta$ in the brains of triple transgenic mice expressing mutated Tau, presenilin 2, and APP [75]. The accumulated A $\beta$ may also directly interact with the $\alpha 7$ nicotinic acetylcholine receptor to form a complex that subsequently induces the activation of PI3K/Akt, which in turn induces the phosphorylation and the activation of GSK-3 $\beta$ (reviewed in [76]). Another hypothesis, reviewed by Mudher and Lovestone [77], suggests that there might be a common cause of both the accumulation of $\mathrm{A} \beta$ and the hyperphosphorylation of Tau molecules; for example, this common cause could be the loss of wnt. 
Regardless, from the diagnostic point of view, these groups of CSF biomarkers (i.e., A $\beta$ peptides and Tau/pTau proteins) should, at this time, be treated as independent and supplementing each other. Another question is whether the value of the diagnostic information provided by increases in CSF Tau is comparable to that provided by decreases in the CSF $\mathrm{A} \beta$ ratio (i.e., should both pieces of information be treated with the same "weight"?) [78]. In an international multicenter project, the combined analysis of $\mathrm{A} \beta 1-42$ and Tau protein resulted in a diagnostic sensitivity of $85 \%$ and a specificity of $58 \%$ in distinguishing AD from non-Alzheimer's types of dementia [52]. In this study, the mean sensitivity and specificity levels of the individual markers were significantly improved from $74-79 \%$ to $86 \%$ when both markers were simultaneously considered. We have found that the discrimination between patients with $\mathrm{AD}$, non-Alzheimer's dementia, and controls is slightly improved when $\mathrm{A} \beta 42$ is combined with $\mathrm{A} \beta 40$ (as the $\mathrm{A} \beta 42 / \mathrm{A} \beta 40$ concentration ratio) [34]. This discrimination was slightly further improved by the simultaneous evaluation of the total Tau CSF concentration; the combination of all three of these parameters resulted in the correct classification of $94 \%$ of the subjects. Also in a recently published study Slaets et al. concluded that adding CSF A $\beta 1-$ 40 and the CSF $\mathrm{A} \beta 1-42 / \mathrm{A} \beta 1-40$ ratio to a biomarker-based decision tree might improve the discrimination between AD and non-AD patients, at least in subjects with intermediate CSF pTau concentrations [79].

2.6. The Role of the AD Biomarkers from the Perspective of the Recent Diagnostic Criteria. In 2011, a set of recommendations were published from the National Institute on Aging-Alzheimer's Association workgroups on diagnostic procedures for $\mathrm{AD}$ [80-83]. One of the most important differences, compared to the previous criteria, is the introduction of the biomarkers of the underlying pathology; however, it has to be stressed that the core clinical criteria of $\mathrm{AD}$ and MCI do not include the use of biomarkers in an everyday routine. This is in contrast with the recommendations of the preclinical $\mathrm{AD}$, intended solely for the research purposes [83]. The most important limitation preventing the application of the CSF and neuroimaging biomarkers in the clinical routine is lack of the validation studies, for example, extended comparison studies. The authors of the American recommendations suggest also additional studies on the biomarkers standardization [81]. It must be stressed that the role of CSF biomarkers in the AD diagnostics is seen differently in other countries, perhaps having longer tradition of the $\mathrm{AD}$ biomarkers research (for example in Germany) that resulted in the acceptance of the CSF biomarkers for the routine diagnostic procedures [84]. The research criteria proposed by Dubois et al. [9] treated abnormalities in the CSF biomarkers as one of the four supportive diagnostic features. The recently recommended harmonized diagnostic criteria, suggested by the Key Symposium workgroup [85], state that the incorporation of molecular and degeneration biomarkers into the clinical routine should be revisited on the completion of standardization efforts.
2.7. Interpretation of the Results in the Context of the Lab-toLab Variability. The simple "copying-and-pasting" of laboratory reference ranges for $\mathrm{AD}$ biomarkers from one diagnostic center to another should be avoided [15]; however, the need to improve comparisons of the results and their interpretations between laboratories led us to propose an interpretation algorithm that can easily be implemented in clinical neurochemistry routine [78]. Briefly, depending on the concentrations of the biomarkers, a numeric score is given, and the final sum (ranging from 0 to 4 points) defines the categorization of a given patient into one of the groups with different probabilities of $\mathrm{AD}$ pathology. This categorization is eventually presented to the physician in an integrated CSF report. The algorithm is method-nonspecific, which means that the ligand-based assays that measure the $\mathrm{A} \beta$ and Tau group biomarkers that, for example, are currently used in our laboratory, can be replaced by assays that are based on different sets of antibodies or even other analytical platforms. If the $\mathrm{A} \beta$ and Tau/pTau results are pathologic, the overall result is interpreted as "neurochemically probable AD." If the results of the NDD analyses of all biomarkers are within the normal ranges, the overall result is interpreted as "no neurochemical evidence of organic CNS disease." Intermediate results (i.e., normal Tau/pTau and abnormal A $\beta$ and vice versa) are interpreted as "neurochemically possible AD." Findings of very high concentrations of Tau are interpreted as "suspected rapidly progressing neurodegeneration, improbable AD," but when accompanied by pathologic $\mathrm{A} \beta$ concentrations/ratios, these same concentrations of Tau shift the interpretation to "neurochemically possible" or even "probable" AD depending on whether the pTau levels are normal. Interestingly, the diagnostic recommendations that were published by the National Institute on Ageing two years after the publication of our algorithm [86] employ almost precisely the same wording and very similar interpretational concepts.

2.8. Early (Preclinical) Diagnosis. The results of the largescale longitudinal studies and meta-analyses show that the CSF alterations typical of AD have a good diagnostic accuracy exceeding $80 \%$ in the discrimination of MCI subjects who will convert to $\mathrm{AD}$ from those who will remain stable or progress to other dementias [87, 88].

Indeed, CSF alterations are currently the earliest observable signs of the disease process. The combination of the Tau, pTau181, and A $\beta 42$ CSF biomarkers can detect incipient $\mathrm{AD}$ among patients who fulfill the criteria for MCI with a sensitivity of $68 \%$ (95\% CI $45-86 \%)$ and a specificity of 97\% (95\% CI 83-100\%), which suggests that it is possible to discriminate the subgroup of patients with MCI who will eventually develop AD [89]. In a follow-up study from the same research group [87], 137 MCI patients and 39 healthy individuals underwent LP at baseline and were clinically followed for 4-6 years. The combination of CSF Tau and A $\beta 1-$ 42 at baseline yielded a sensitivity of $95 \%$ and a specificity of $83 \%$ for the detection of incipient $\mathrm{AD}$ in patients with $\mathrm{MCI}$ and revealed an increased relative risk of progression to $\mathrm{AD}$ for the MCI cases with pathologic Tau and $\mathrm{A} \beta 1-42$ 
levels at baseline (hazard ratio 17.7, $P<0.0001$ ). The combination of Tau and the A $\beta 1-42 /$ pTau 181 ratio yielded similar results (sensitivity $95 \%$, specificity $87 \%$, and hazard ratio 19.8). Similarly, in our study, the cut-off levels for $A \beta 1-42$ and pTaul81 derived from the differential analysis of early dementia patients and applied to the results obtained from the MCI group allowed for the definition of a subgroup of subjects without $\mathrm{AD}$ but with an increased risk of developing the disease [90].

A recently published meta-analysis revealed that the combination of $A \beta 1-42$ and Tau yielded the best predictive accuracy for the conversion of MCI into $\mathrm{AD}$ (odds ratio 18.1). A $\beta$, total Tau, and phosphorylated Tau in the CSF also predicted conversion but did so with lower accuracies (odds ratios: 7.5 to 8.1 ) [91].

An interesting graphic summary of the dynamics of the biomarker alterations in $\mathrm{AD}$ was proposed by Jack et al. [92]. The first alterations characteristic of $\mathrm{AD}$ occur in the amyloid $\beta$ pathway and can be observed as decreases in the concentrations of $\mathrm{A} \beta 42$ in the CSF and/or the deposition of $\mathrm{A} \beta$ plaques in the brain on Pittsburgh Compound $\mathrm{B}(\mathrm{PiB})$ PET scans in the early preclinical phase. Neuropathologic findings of significant $\mathrm{A} \beta$ depositions in the brains of cognitively normal people further support the concept that the $\mathrm{A} \beta$ pathology precedes the clinical symptoms [93]. Increases in Tau concentrations in the CSF occur later and perhaps as a consequence of the accumulation of $\mathrm{A} \beta$ pathology. Indeed, one hypothesis proposes that extracellular $\mathrm{A} \beta$ depositions in $\mathrm{AD}$ influence the clearance of Tau that is released from dying neurons [94]. At the stage of the disease at which the first clinical symptoms are observable (i.e., in MCI), the intensity of the $\mathrm{A} \beta$ pathology does not correlate with the clinical and cognitive symptoms, and only a weak correlation between Tau concentrations and cognitive functions is observed [34, 95]. These findings further support the hypothesis that amyloid $\beta$ and, to a lesser degree, Tau reach plateaus prior to the onset of the first clinical symptoms.

On the other hand, neuropathologic evidence recently summarized by Musiek and Holtzman [96] suggests a different temporal order of the events: tauopathy seems to begin early in life and accumulate slowly with age, while the $\mathrm{A} \beta$ pathology starts later and sets in motion a pathophysiologic cascade of events leading to AD. This is in agreement with the data of Braak and Braak, who demonstrated that tau pathology occurred in limbic regions of young, cognitively normal individuals and usually preceded any amyloid pathology [14]. Musiek and Holtzman hypothesize further that the tauopathy occurs as a result of age along a predefined spatial path starting in the brainstem and medial temporal lobe. On the other hand, $\mathrm{A} \beta$ pathology begins in the default mode network, which has considerable synaptic connectivity with the hippocampus. This suggests that $\mathrm{A} \beta$ might affect the medial temporal lobe via transsynaptic mechanisms, which in turn could stimulate tauopathy, accelerating tangle formation and spread along its usual spatial course. It is further hypothesized that the appearance of $\mathrm{A} \beta$ pathology can accelerate tauopathy [8].

In a recently published study, the diagnostic power of the combination of $\mathrm{A} \beta$, Tau, and pTau (expressed as an "AD-CSF
Index") discriminated autopsy-confirmed AD patients from controls with the sensitivity and specificity exceeding $80 \%$ [97]. On the other hand, thinking of neuropathological examination as a "golden standard" of the diagnosis of $\mathrm{AD}$ is criticized [98].

2.9. Lack of Alterations in Young Nondemented Subjects. Since the first alterations in $\mathrm{AD}$ occur decades before onset of clinical symptoms in amyloid $\beta$ pathway, it was interesting for us to correlate the concentrations of $\mathrm{A} \beta$ peptides and apolipoprotein E (APOE) genotype in young nondemented persons [99]. This was brought about by the fact that APOE genotype is a strong risk factor for $\mathrm{AD}$, which means that a group consisting of APOE $\varepsilon 4$ carriers is statistically significantly enriched in persons who will develop $\mathrm{AD}$ in contrast with a group of noncarriers. Correspondingly, our working hypothesis was that if the pathomechanisms of neurodegeneration are occurring very early (30-40 years before the onset of dementia), the concentrations of the $\mathrm{A} \beta 42$ peptides should be decreased in the group of APOE $\varepsilon 4$ carriers. We did not find any alterations of the concentrations of $\mathrm{A} \beta$ peptides in plasma of young volunteers without cognitive dysfunctions, irrespectively of their APOE genotype and history of dementia in their families, and we cautiously concluded that these alterations do not occur that early [99]. These results are in line with the report by Popp et al., showing no differences in the CSF A $\beta 1-42$ concentrations between young (16-45 years old) nondemented carriers and noncarriers of the $\varepsilon 4$ allele; however, statistically significant difference was observed in this study in the middle-aged persons [100]. Furthermore, Khan et al. reported recently no differences in volume of hippocampus between healthy adolescents carrying and noncarrying $\varepsilon 4$ allele [101].

Interestingly, the dynamics of the biomarkers alterations observed in autosomal dominant $\mathrm{AD}$ showed that the first pathologic event was actually an increase of the $\mathrm{A} \beta 42$ concentrations in the CSF, followed by its steady normalization, and eventually a decrease. On the other hand, $\mathrm{A} \beta 42$ concentrations in plasma seem to be elevated throughout the range of estimated years from expected symptom onset [102].

Although this review focuses on the role of CSF biomarkers, the diagnostic role of neuroimaging is worth mentioning, particularly in the context of the correlations between neuroimaging results and fluid biomarkers. Cerebral atrophy and decreased glucose metabolism can be detected in AD patients by MRI and FDG-PET $[83,103,104]$, but it should be stressed that only $\mathrm{A} \beta$ PET imaging is specific for the amyloid pathology of AD [103]. On the other hand, in spite of the fact that several amyloid imaging probes are currently at various stages of approval, a number of factors appear to limit their clinical utilization [105]. Taken together, although clinical studies have shown that baseline imaging and CSF biomarkers are independently associated with cognitive decline [95], only the combination of neuroimaging techniques, such as MRI and FDG-PET, with neurochemical dementia diagnostic tools can increase the sensitivity of prodromal AD diagnoses $[95,106,107]$. 
2.10. Sample Handling Procedures and the Quality Control (QC) Programs. Many studies have addressed the issue of preanalytical sample handling for the reliable measurement of NDD biomarkers. Schoonenboom et al. [108] found $20 \%$ decreases in A $\beta 1-42$ concentrations after two days at 4, 18 , and $37^{\circ} \mathrm{C}$ or after three freeze/thaw cycles, whereas the concentration of Tau did not decrease over 12 days at $37^{\circ} \mathrm{C}$ or after six freeze/thaw cycles. Sjögren et al. found no significant differences in $\mathrm{A} \beta 42$ or Tau concentrations between fresh and once-thawed CSF samples [39]. Marked declines in A $\beta$ were detected between the first and second freeze/thaw cycles in the studies of Jensen et al. and Vanderstichele et al. [109, 110].

Careful elaboration of the protocols for the correct collection, handling, and shipping of samples for NDD analyses is particularly important for two reasons. First, a substantial advantage of neurochemical dementia diagnostics is that the analysis of CSF (or any other body fluid) does not require the presence of the patient. LP is a simple procedure that can be performed in every hospital, and the acquired sample can be shipped to an expert center (or multiple centers when necessary) while the patient remains at home (or in a nonexpert hospital). To utilize this advantage and to standardize the preparation and shipment of the material, preanalytical sample handling procedures must be carefully elaborated. Second, the physical-chemical properties of the molecules in question (especially $\mathrm{A} \beta$ peptides) make them highly vulnerable to preanalytical errors that can lead to incorrect interpretations of the results. For example, maintaining a CSF sample in a polystyrene test tube for fewer than 30 minutes is sufficient to cause the adsorption of $\mathrm{A} \beta$ molecules into the test tube's wall, which artificially decreases $\mathrm{A} \beta$ concentrations, which in turn would produce serious errors in the interpretation of the results.

A working group of European and American scientists addressed several preanalytical issues that could potentially influence the accuracy of the measurement of AD biomarkers and produced a consensus guideline paper [111]. For example, conflicting results regarding the diurnal variations in NDD biomarker concentrations were critically discussed $[112,113]$; however, because the data supporting a lack of circadian variations in these biomarkers seemed more convincing than the data favoring such variations, no recommendations regarding the time of day at which LPs should be performed were provided. Similarly, despite the rostrocaudal concentration gradients of the brain-derived proteins in the CSF that have been postulated elsewhere, no differences in biomarker concentrations in the fractionated CSF samples were observed, and recommendations regarding which fraction should be taken for analysis were deemed unnecessary. On the other hand, however, the collection of a minimum of $1.5 \mathrm{~mL}$ of CSF was recommended to ensure the sufficient availability of material should repeated analyses be necessary. Because there is no evidence that NDD biomarkers are influenced by food intake or glucose levels and because asking elderly individuals to fast overnight prior to the LP can often be problematic, the consensus that fasting is not required for $\mathrm{AD}$ biomarker analyses was reached. In contrast, the issue of the test tube material seemed to be even more complex than previously postulated. Indeed, the vast majority of the "polypropylene" test tubes available on the market are made of copolymers [114], which further complicates direct comparisons of different test tubes. To reduce the possibility of surface adsorption, the recommendation that the working group use tubes of the smallest volume possible and fill those tubes to at least half of their volume was made. However, the empirical evidence supporting this recommendation is lacking, and further studies are necessary to clarify this issue. Perhaps the most critical preanalytical issues, aside from the issue of the test tube material, are the storage time before freezing and the repetition of freeze/thaw cycles. The former issue is of particular practical relevance because it influences the manner in which CSF samples should be shipped to distant laboratories (e.g., frozen on dry ice or in ambient temperatures). Because the available data suggest that the stabilities of the biomarkers in CSF samples stored at room temperature are reasonable for at least five days ([115] and based on unpublished data from the group of S. Engelborghs), it was recommended that the CSF samples can be sent by regular post if the transportation time does not exceed five days. Repeated freeze/thaw cycles should generally be avoided; however, one or perhaps even two freeze/thaw cycles do not seem to dramatically influence the biomarker concentrations $[113,115]$. Once frozen at $-80^{\circ} \mathrm{C}$, the NDD biomarkers are stable for years if they are not thawed and refrozen $[113,115]$.

Due to the physical-chemical properties of $\mathrm{A} \beta$ peptides and Tau proteins, QC of NDD analyses is extremely difficult. For example, up to today a certified QC sample for any of the NDD biomarkers is not available on the market, which further complicates the situation in countries in which the regulations regarding laboratory QC are legally binding (e.g., Germany [116]). Moreover, the normative regulations that describe the requirements for the quality and competence of medical laboratories (ISO 15189) and the competence of calibration laboratories (ISO 17025) further focus attention on QC issues [117]. Large-scale international scientific studies have shown that the interlaboratory precisions of NDD measurements require further optimization $[15,118]$. Thus, situations in which properly prepared and distributed certified QC material is lacking can be described as vicious circles.

In 2006, we published the results of what was likely the first international QC survey of NDD biomarkers [15]. A ventricular CSF sample was collected from a neurosurgical patient, aliquoted, and shipped to fourteen laboratories with the request that these laboratories analyze the biomarkers under their routine conditions. We observed coefficients of variation in the range of $21 \%$ to $38 \%$. Three years later, Verwey et al. published a similar study [118] that also included data about longitudinal stability and confirmed our interlaboratory variation results; however, only after the introduction of the world-wide Alzheimer's Association QC Project (coordinated by K. Blennow, University of Göteborg, $[119,120])$, a large portion of the interlaboratory comparison problems could be solved. This project was prospectively defined and is being conducted as a long-term study with regular runs that occur three times per year, which not only enables the examination of particular situations in particular 
laboratories at particular times, but also enables long-term follow-ups of performance. Moreover, a large set of the information collected by the coordinators that includes not only the concentrations measured by the participants but also the batch numbers of the assays and calibrators, data about the internal controls, and data about the experimenters' experience with the analyses enables complex and multidimensional analyses of the reported data. However, it should be stressed that not all of the relevant issues are covered by this project; for example, the samples are shipped frozen, which is not always the situation for routine diagnostics, and the samples are maintained in conditions that are not controllable by the project coordinator for three to ten months because the set of QC samples for a given year is shipped at the beginning of that year. Considering the latter point, if we were able to assign objective QC "target values" to the samples (which would reference a measurement method if it was available), a perfect value would indicate that the quality of both the analytical procedures and the storage conditions had been controlled. In situations in which this "target value" represented an average of the results from all participants, nonoptimal storage conditions (or performances) by one or two outliers might influence the overall results.

\section{Remarks on Strategies for the Validation of Novel Candidate Biomarkers}

In the diagnosis of $\mathrm{AD}$, sensitivity and specificity are of equal importance. A reasonable sensitivity is necessary to identify as many $\mathrm{AD}$ patients as possible and to minimize the occurrence of false negatives. High specificity is also necessary to assure diagnostic accuracy by excluding non$\mathrm{AD}$ patients and hence minimizing false positive diagnoses. In 1998, an expert consortium suggested that useful $A D$ biomarkers should have specificities of $75-85 \%$ or more [121], and the European Medicines Agency (EMA) recently stated that AD CSF biomarkers were useful for the enrichment of the prodromal $\mathrm{AD}$ populations in the clinical trials [122].

Regardless of the technology used to develop new biomarkers or to improve existing ones, some crucial issues must be considered in the proper planning of validation experiments. First, no gold standard for AD diagnosis exists (for a more detailed discussion, see, e.g., [98]). The presence of plaques and tangles upon neuropathologic examination is considered the gold standard by some authors, but the following critiques of this view are notable: (a) neither plaques nor tangles are pathognomonic for $\mathrm{AD}$ and (b) the times between the diagnostic LP and the neuropathologic confirmation of the diagnosis can be as long as ten years. Thus, straightforward correlations between CSF findings and neuropathologic findings are reliable only in cases of rapidly progressing brain disorders (e.g., CJD), extremely rare $\mathrm{AD}$ cases in which a patient dies for other reasons shortly after LP, or unique situations in which brain biopsies are performed. The difficulty of correlating CSF and neuropathologic examination findings has important consequences. First, it is unlikely that biomarkers (or combinations of biomarkers) with $100 \%$ sensitivity and $100 \%$ specificity will be found because errors in the categorization of patients and groups are made at the beginning of each study, and post hoc correction of these errors is not possible. Second, "surrogate strategies" that seek to characterize the groups as accurately as possible must be considered. For example, in our center, patients enter "AD" or "control" groups only when their clinical/neuropsychological diagnoses that are supported by corresponding neuroimaging findings remain in accordance with their CSF findings. These "AD supported by positive NDD" and "controls supported by negative NDD" groups are further confirmed by the finding of a higher percentage of APOE $\varepsilon 4$-allele carriers in the $\mathrm{AD}$ group. Thus, we apply a type of three-dimensional stratification strategy that includes clinical, neurochemical, and genetic dimensions. For example, samples from patients who have been clinically diagnosed as having $\mathrm{AD}$ but do not exhibit clear alterations in their CSF are not used for biomarker discovery experiments. We are aware of one of the serious drawbacks of this strategy, namely, that it is based on the assumption that all AD subjects have alterations in their CSF and that the "controls" do not.

The preclinical phase of Alzheimer's disease can last up to twenty years, which is relevant to the second issue about NDD biomarker discovery; it is probable that the individuals who are defined as "healthy" (i.e., those categorized as "controls") will include subjects in which the pathobiochemical mechanisms are already occurring although neither subjective nor objective cognitive dysfunctions are observable. Therefore, it is important to distinguish between "Alzheimer's disease" and "dementia in the course of AD." A good strategy for avoiding the error of including ill subjects in the "control" group is to observe them for a certain time period; this strategy is successfully applied by many centers, although it has the drawbacks of requiring longer observation times and reductions in the number of study patients due to dropouts.

The third important consideration is linked to the fact that some of the biomarkers already known (e.g., A $\beta$ peptides) are quite sensitive for preanalytical handling, and there is actually no good reason to believe that the biomarkers we are searching for will be more robust. Furthermore, certain aspects of the CSF physiology must not be ignored; for example, as discussed above the CSF does not actually "circulate" (as does blood); rather, its "portion" is generated as an ultrafiltrate of the blood, it flows through specific anatomic compartments of the CNS, and it is eliminated into the blood without returning to its place of origin. Thus, there are substantial differences between the composition of the CSF in the ventricular and lumbar regions (i.e., rostrocaudal gradients are present) because the diffusion of brain-derived proteins (from the CSF into the blood) and blood-derived proteins (from the blood into the CSF) along the pathway of the flow of the CSF results in alterations in the concentrations of nearly all of the proteins in the CSF.

Taken together this discussion stresses the importance of using only prospectively collected samples that have been handled according to proper standardized operating procedures. In multicenter studies, these standardized operating procedures should be presented to all participants at the beginning of the study and should be regularly controlled thereafter by a group of experts. Only samples handled in 
this manner can be considered suitable for studies seeking to discover new AD biomarkers.

\section{4. "Biomarkers" in the Blood}

As previously stated, LP is a relatively safe and uncomplicated procedure; nevertheless, follow-up LP and the measurement of CSF biomarkers are generally considered to be inconvenient for patients. Additionally, if disease-modifying therapies are discovered, it is plausible that they will be most effective in the early (i.e., preclinical) stage, which, in turn, would suggest that the use of more easily accessible body fluids would favor earlier diagnoses and result in at-risk patients being identified and sent to expert centers for advanced diagnostic procedures (including LP) and treatment.

Thus, searches for relevant biomarkers in alternative body fluids are required. Given that the earliest pathophysiologic processes of $\mathrm{AD}$ likely involve $\mathrm{A} \beta$ metabolism and the corresponding earliest biomarkers likely involve the $\mathrm{A} \beta$ pathway, it is not surprising that the vast majority of studies of potential $\mathrm{AD}$ biomarkers in the blood have concentrated on $\mathrm{A} \beta$ peptides. Importantly, $\mathrm{A} \beta$ peptides are measureable in the blood, although the results of the studies in this are discrepant as discussed later in this section. On the other hand, the methods available to measure Tau concentrations in the blood are not widespread. To the best of my knowledge, there is currently (January 2014) only one study available that has reported a reliable method for the measurement of Tau concentrations in human blood [123].

Blood and blood-derived fluids (i.e., serum and plasma) would fulfill the criteria for such a biomarker source for the following reasons: (a) several brain-derived factors have been found to be present in the blood because the CSF stays in direct contact with the blood while it is in the spinal canal [124]; (b) according to the concept of Felgenhauer, the brain-derived factors released in the regions of brain far from the ventricles may predominantly leave the brain parenchyma through the blood-brain barrier into the blood rather than through the brain-CSF barrier into the CSF [125]; (c) the parenteral administration of $\mathrm{A} \beta$-specific monoclonal antibody facilitates rapid effluxes of brain-derived $\mathrm{A} \beta 40$ and $A \beta 42$ into the plasma in a transgenic mouse model expressing the human mutated amyloid precursor protein gene $[126,127]$; and (d) $A \beta$ seems to be eliminated from the human brain parenchyma primarily into the leptomeningeal arteries [128]. Furthermore, some evidence suggests that $\mathrm{A} \beta$ peptides are released from tissues other than the brain [129, 130]; hence, it is interesting to speculate that alterations in the concentrations of $\mathrm{A} \beta$ peptides released from nonbrain tissue(s) might also be useful in the diagnosis of AD. In our pilot study using $\mathrm{A} \beta$-SDS-PAGE/immunoblot, we observed the presence of all of the $\mathrm{A} \beta$ peptides that are known to constantly be present in the CSF (i.e., 1-37/38/39/40/42) in the plasma. Furthermore, we also observed an additional peptide in the plasma that was not found in the CSF (most likely $\mathrm{A} \beta 2-40)$ [131]. In a follow-up study, we observed a complex pattern of $\mathrm{A} \beta$ peptides of different amino acid sequences that included both $\mathrm{N}$ - and C-terminus-truncated forms [132].
A few large (i.e., hundreds to thousands of subjects) studies published in the last decade have addressed alterations in plasma $\mathrm{A} \beta$ peptides as potential biomarkers of $\mathrm{AD}$. Van Oijen et al. [50] reported an association between increased plasma A $\beta 40$ concentrations and an increased risk of dementia, particularly in subjects with concomitantly low concentrations of $\mathrm{A} \beta 42$. Individuals with high concentrations of $\mathrm{A} \beta 40$ and low concentrations of $\mathrm{A} \beta 42$ had a risk of dementia that was over tenfold higher than that of persons with low concentrations of both $\mathrm{A} \beta 40$ and $\mathrm{A} \beta 42$. Interestingly, these findings were independent of the presence of an APOE $\varepsilon 4$ allele. Similarly, Mayeux et al. [133] reported higher baseline plasma $\mathrm{A} \beta 40$ and $\mathrm{A} \beta 42$ concentrations in individuals who developed $\mathrm{AD}$ compared to elderly people who did not develop the disease over the five-year observation time of that study. Moreover, after adjusting for $\mathrm{A} \beta 40$ concentrations, $\mathrm{A} \beta 42$ concentrations remained significantly different.

In another study [49] baseline $\mathrm{A} \beta 40$ and $\mathrm{A} \beta 42$ concentrations were measured in the plasma of an elderly cohort of 563 volunteers who were then followed for 2-12 years. Of these individuals, 53 subjects developed MCI or AD, and the subjects with plasma $\mathrm{A} \beta 42 / \mathrm{A} \beta 40$ ratios in the lower quartiles were at a significantly elevated risk for the development of MCI or AD. A comparison of the subjects with plasma $\mathrm{A} \beta 42 / \mathrm{A} \beta 40$ ratios in the lowest and the highest quartiles produced a relative risk of 3.1, and this observation suggests that the plasma $\mathrm{A} \beta 42 / \mathrm{A} \beta 40$ ratio may be a useful biomarker for identifying cognitively normal elderly subjects who are at an increased risk for developing cognitive disturbances.

Interestingly, in contrast with these studies, Freeman et al. [134] compared the plasma levels of $\mathrm{A} \beta 40$ and $\mathrm{A} \beta 42$ as measured intravitam with the biochemical and pathological alterations of the frontal and temporal neocortices in 25 individuals, including 17 subjects with $\mathrm{AD}$ who died at a median of one year after the blood collection; these authors found no association between plasma $\mathrm{A} \beta$ peptide levels and any other brain measures.

An interesting report on the possible disturbances of the CSF/plasma A $\beta$ equilibrium was published by Giedraitis et al. [135], who measured $A \beta 40$ and $A \beta 42$ concentrations in paired samples of blood and CSF from patients with AD (39 subjects), MCI (29 subjects), and healthy controls (18 subjects) and observed a correlation between CSF and plasma concentrations of both $\mathrm{A} \beta$ peptides in healthy individuals, whereas no such correlation was observed in the AD or MCI patients.

In a large, cross-sectional study, Sun et al. [136] found an association between decreased plasma A $\beta 42$ concentrations and depression, which, from the cognitive perspective, suggests the presence of at least two depression subtypes: (a) amyloid-associated depression, which is associated with poor memory and other cognitive dysfunctions, and (b) nonamyloid depression, which is associated only with visuospatial and executive dysfunctions. Together with the fact that depression is quite often a prodromal stage of dementia [137], these authors' finding of decreased plasma $A \beta 42$ in patients with depression and memory complaints, but not in patients with depression without cognitive disturbances, 
might suggest that they found a group of patients in whom depression was the first symptom of impending dementia.

In our study [48], highly significant decreases in plasma $\mathrm{A} \beta 1-42$ concentrations and $\mathrm{A} \beta 1-42 / \mathrm{A} \beta 1-40$ ratios were observed in patients with early $\mathrm{AD}$ or $\mathrm{MCI}$ of the $\mathrm{AD}$ type compared to patients with other types of dementia. A decrease in the plasma $\mathrm{A} \beta 1-42 / \mathrm{A} \beta 1-40$ ratio was observed in the AD group relative to those with other types of dementia in this study, and similar decreases in the $\mathrm{A} \beta 42 / \mathrm{A} \beta 40$ ratio have been observed in other prospective studies using different antibodies and similar assays $[49,50]$. However, in a previously published report, Hansson and colleagues found no significant alterations in A $\beta 42$ plasma concentrations [138]. Together, these observations further strengthen the hypothesis that blood $\mathrm{A} \beta$ concentrations might be affected in AD patients, although it must be stressed that it is too early to clearly predict the value of the blood $\mathrm{A} \beta$ concentration as a diagnostic tool.

In a recent meta-analysis of fourteen studies on the potential diagnostic value of $\mathrm{A} \beta$ peptides in the plasma, Koyama et al. [139] concluded that the plasma A $\beta 42 / 40$ concentration ratio might help to predict the risk of developing dementia, although the interstudy heterogeneity must be taken into account.

Perhaps one of the most important issues that has resulted in the discrepant results of studies of $\mathrm{A} \beta$ concentrations in the plasma is the standardization of preanalytical sample handling. In a recently published review, Watt et al. [140] defined several potential sources of variability in $A \beta$ concentrations in the plasma that included the following: (a) the effect of fasting, (b) the effect of anticoagulants, (c) the use of different types of collection tubes, (d) the manner in which the blood is processed, and (e) the manner in which the blood is stored.

\section{Conflict of Interests}

The authors declare that there is no conflict of interests regarding the publication of this paper.

\section{Acknowledgments}

Piotr Lewczuk is supported by a Grant from the German Bundesministerium für Bildung und Forschung (01ED1203D) within the BiomarkAPD Project of the JPND, holds the position of Visiting Professor at the Medical University of Bialystok (Poland), and has received consultation and/or lecture honoraria from Innogenetics, IBL International, AJ Roboscreen, Roche, Beckman Coulter, and Merz.

\section{References}

[1] J. Hort, J. T. O'Brien, G. Gainotti et al., "EFNS guidelines for the diagnosis and management of Alzheimer's disease," European Journal of Neurology, vol. 17, no. 10, pp. 1236-1248, 2010.

[2] W. Thies and L. Bleiler, "2011 Alzheimer's disease facts and figures," Alzheimer's and Dementia, vol. 7, no. 2, pp. 208-244, 2011.
[3] Alzheimer's Association, "2010 Alzheimer's disease facts and figures," Alzheimer's \& Dementia: The Journal of the Alzheimer's Association, vol. 6, no. 2, pp. 158-194, 2010.

[4] K. Blennow, M. J. de Leon, and H. Zetterberg, "Alzheimer's disease," The Lancet, vol. 368, no. 9533, pp. 387-403, 2006.

[5] M. J. de Leon, J. Golomb, A. E. George et al., "The radiologic prediction of Alzheimer disease: the atrophic hippocampal formation," American Journal of Neuroradiology, vol. 14, no. 4, pp. 897-906, 1993.

[6] H. Braak and E. Braak, "Frequency of stages of Alzheimerrelated lesions in different age categories," Neurobiology of Aging, vol. 18, no. 4, pp. 351-357, 1997.

[7] M. J. de Leon, A. Convit, O. T. Wolf et al., "Prediction of cognitive decline in normal elderly subjects with 2-[18F]fluoro-2deoxy-D-glucose/positron-emission tomography (FDG/PET)," Proceedings of the National Academy of Sciences of the United States of America, vol. 98, no. 19, pp. 10966-10971, 2001.

[8] J. L. Price and J. C. Morris, "Tangles and plaques in nondemented aging and "preclinical" Alzheimer's disease," Annals of Neurology, vol. 45, no. 3, pp. 358-368, 1999.

[9] B. Dubois, H. H. Feldman, C. Jacova et al., "Research criteria for the diagnosis of Alzheimer's disease: revising the NINCDSADRDA criteria," Lancet Neurology, vol. 6, no. 8, pp. 734-746, 2007.

[10] R. C. Petersen, P. S. Aisen, L. A. Beckett et al., "Alzheimer's disease neuroimaging initiative (ADNI): clinical characterization," Neurology, vol. 74, no. 3, pp. 201-209, 2010.

[11] J. M. Torpy, C. Lynm, and R. M. Glass, "JAMA patient page. Mild cognitive impairment," The Journal of the American Medical Association, vol. 302, no. 4, p. 452, 2009.

[12] C. D. Aluise, R. A. Sowell, and D. A. Butterfield, "Peptides and proteins in plasma and cerebrospinal fluid as biomarkers for the prediction, diagnosis, and monitoring of therapeutic efficacy of Alzheimer's disease," Biochimica et Biophysica Acta-Molecular Basis of Disease, vol. 1782, no. 10, pp. 549-558, 2008.

[13] T. G. Beach, S. E. Monsell, L. E. Phillips, and W. Kukull, "Accuracy of the clinical diagnosis of Alzheimer disease at National Institute on Aging Alzheimer Disease Centers, 20052010," Journal of Neuropathology and Experimental Neurology, vol. 71, no. 4, pp. 266-273, 2012.

[14] H. Braak and E. Braak, "Neuropathological stageing of Alzheimer-related changes," Acta Neuropathologica, vol. 82, no. 4, pp. 239-259, 1991.

[15] P. Lewczuk, G. Beck, O. Ganslandt et al., "International quality control survey of neurochemical dementia diagnostics," Neuroscience Letters, vol. 409, no. 1, pp. 1-4, 2006.

[16] H. Reiber, "Flow rate of cerebrospinal fluid (CSF) - a concept common to normal blood-CSF barrier function and to dysfunction in neurological diseases," Journal of the Neurological Sciences, vol. 122, no. 2, pp. 189-203, 1994.

[17] H. Reiber and J. B. Peter, "Cerebrospinal fluid analysis: diseaserelated data patterns and evaluation programs," Journal of the Neurological Sciences, vol. 184, no. 2, pp. 101-122, 2001.

[18] H. Hampel, H. U. Kötter, F. Padberg, D. A. Körschenhausen, and H. Möller, "Oligoclonal bands and blood-cerebrospinalfluid barrier dysfunction in a subset of patients with Alzheimer disease: comparison with vascular dementia, major depression, and multiple sclerosis," Alzheimer Disease and Associated Disorders, vol. 13, no. 1, pp. 9-19, 1999.

[19] R. Zimmermann, G. Beck, S. Knispel et al., "Intrathecal IgG synthesis in patients with alterations in the neurochemical 
dementia diagnostics," Journal of Alzheimer's Disease, vol. 19, no. 4, pp. 1199-1203, 2010.

[20] H. Zetterberg, K. Tullhög, O. Hansson, L. Minthon, E. Londos, and K. Blennow, "Low incidence of post-lumbar puncture headache in 1,089 consecutive memory clinic patients," European Neurology, vol. 63, no. 6, pp. 326-330, 2010.

[21] E. Peskind, A. Nordberg, T. Darreh-Shori, and H. Soininen, "Safety of lumbar puncture procedures in patients with Alzheimer's disease," Current Alzheimer Research, vol. 6, no. 3, pp. 290-292, 2009.

[22] D. Alcolea, P. Martinez-Lage, A. Izagirre et al., "Feasibility of lumbar puncture in the study of cerebrospinal fluid biomarkers for Alzheimer's disease: a multicenter study in Spain," Journal of Alzheimer's Disease, vol. 39, pp. 719-726, 2014.

[23] J. Popp, M. Riad, K. Freymann, and F. Jessen, "Diagnostic lumbar puncture performed in the outpatient setting of a memory clinic: frequency and risk factors of post-lumbar puncture headache," Nervenarzt, vol. 78, no. 5, pp. 547-551, 2007.

[24] J. Kang, H.-G. Lemaire, and A. Unterbeck, "The precursor of Alzheimer's disease amyloid A4 protein resembles a cell-surface receptor," Nature, vol. 325, no. 6106, pp. 733-736, 1987.

[25] P. K. Panegyres, "The amyloid precursor protein gene: a neuropeptide gene with diverse functions in the central nervous system," Neuropeptides, vol. 31, no. 6, pp. 523-535, 1997.

[26] M. Citron, T. S. Diehl, G. Gordon, A. L. Biere, P. Seubert, and D. J. Selkoe, "Evidence that the 42- and 40-amino acid forms of amyloid $\beta$ protein are generated from the $\beta$-amyloid precursor protein by different protease activities," Proceedings of the National Academy of Sciences of the United States of America, vol. 93, no. 23, pp. 13170-13175, 1996.

[27] H.-W. Klafki, D. Abramowski, R. Swoboda, P. A. Paganetti, and M. Staufenbiel, "The carboxyl termini of $\beta$-amyloid peptides 1-40 and 1-42 are generated by distinct $\gamma$-secretase activities," Journal of Biological Chemistry, vol. 271, no. 45, pp. 2865528659, 1996.

[28] S. F. Lichtenthaler, D. Beher, H. S. Grimm et al., "The intramembrane cleavage site of the amyloid precursor protein depends on the length of its transmembrane domain," Proceedings of the National Academy of Sciences of the United States of America, vol. 99, no. 3, pp. 1365-1370, 2002.

[29] H. Jang, F. T. Arce, S. Ramachandran et al., "Truncated $\beta$ amyloid peptide channels provide an alternative mechanism for Alzheimer's Disease and Down syndrome," Proceedings of the National Academy of Sciences of the United States of America, vol. 107, no. 14, pp. 6538-6543, 2010.

[30] C. M. Carlsson, "Type 2 diabetes mellitus, dyslipidemia, and Alzheimer's disease," Journal of Alzheimer's Disease, vol. 20, no. 3, pp. 711-722, 2010.

[31] G. Taubes, "Insulin insults may spur Alzheimer's disease," Science, vol. 301, no. 5629, pp. 40-41, 2003.

[32] G. S. Watson, E. R. Peskind, S. Asthana et al., "Insulin increases CSF A $\beta 42$ levels in normal older adults," Neurology, vol. 60, no. 12, pp. 1899-1903, 2003.

[33] M. Karczewska-Kupczewska, N. Lelental, A. Adamska et al., "The influence of insulin infusion on the metabolism of amyloid b peptides in plasma," Alzheimer's and Dementia, vol. 9, no. 4, pp. 400-405, 2013.

[34] P. Lewczuk, H. Esselmann, M. Otto et al., "Neurochemical diagnosis of Alzheimer's dementia by CSF A $\beta 42, \mathrm{~A} \beta 42 / \mathrm{A} \beta 40$ ratio and total tau," Neurobiology of Aging, vol. 25, no. 3, pp. 273281, 2004.
[35] L. M. Shaw, H. Vanderstichele, M. Knapik-Czajka et al., "Qualification of the analytical and clinical performance of CSF biomarker analyses in ADNI," Acta Neuropathologica, vol. 121, no. 5, pp. 597-609, 2011.

[36] P. Lewczuk and J. Kornhuber, "Neurochemical dementia diagnostics in Alzheimer's disease: where are we now and where are we going?” Expert Review of Proteomics, vol. 8, no. 4, pp. 447458, 2011.

[37] R. Motter, C. Vigo-Pelfrey, D. Kholodenko et al., "Reduction of $\beta$-amyloid peptide 42 in the cerebrospinal fluid of patients with Alzheimer's disease," Annals of Neurology, vol. 38, no. 4, pp. 643-648, 1995.

[38] J. Wiltfang, H. Esselmann, A. Smirnov et al., " $\beta$-amyloid peptides in cerebrospinal fluid of patients with CreutzfeldtJakob disease," Annals of Neurology, vol. 54, no. 2, pp. 263-267, 2003.

[39] M. Sjögren, M. Gisslén, E. Vanmechelen, and K. Blennow, "Low cerebrospinal fluid $\beta$-amyloid 42 in patients with acute bacterial meningitis and normalization after treatment," Neuroscience Letters, vol. 314, no. 1-2, pp. 33-36, 2001.

[40] P. E. Spies, M. M. Verbeek, T. Van Groen, and J. A. H. R. Claassen, "Reviewing reasons for the decreased CSF Abeta42 concentration in Alzheimer disease," Frontiers in Bioscience, vol. 17, no. 6, pp. 2024-2034, 2012.

[41] P. Lewczuk, H. Esselmann, M. Meyer et al., "The amyloid$\beta(\mathrm{A} \beta)$ peptide pattern in cerebrospinal fluid in Alzheimer's disease: evidence of a novel carboxyterminally elongated $\mathrm{A} \beta$ peptide," Rapid Communications in Mass Spectrometry, vol. 17, no. 12, pp. 1291-1296, 2003.

[42] T. Tapiola, H. Soininen, and T. Pirttilä, "CSF tau and A $\beta 42$ levels in patients with Down's syndrome," Neurology, vol. 56, no. 7, p. 979, 2001.

[43] P. Lewczuk, H. Kamrowski-Kruck, O. Peters et al., "Soluble amyloid precursor proteins in the cerebrospinal fluid as novel potential biomarkers of Alzheimer's disease: a multicenter study," Molecular Psychiatry, vol. 15, no. 2, pp. 138-145, 2010.

[44] P. Lewczuk, J. Popp, N. Lelental et al., "Cerebrospinal fluid soluble amyloid- $\beta$ protein precursor as a potential novel biomarkers of Alzheimer's disease," Journal of Alzheimer's Disease, vol. 28, no. 1, pp. 119-125, 2012.

[45] A. Pérez, L. Morelli, J. C. Cresto, and E. M. Castaño, “Degradation of soluble amyloid $\beta$-peptides 1-40, 1-42, and the Dutch variant $1-40 \mathrm{Q}$ by insulin degrading enzyme from Alzheimer disease and control brains," Neurochemical Research, vol. 25, no. 2, pp. 247-255, 2000.

[46] M. M. Wilhelmus, I. Otte-Höller, J. J. J. Van Triel et al., "Lipoprotein receptor-related protein-1 mediates amyloid- $\beta$ mediated cell death of cerebrovascular cells," American Journal of Pathology, vol. 171, no. 6, pp. 1989-1999, 2007.

[47] R. Deane, R. D. Bell, A. Sagare, and B. V. Zlokovic, "Clearance of amyloid- $\beta$ peptide across the blood-brain barrier: implication for therapies in Alzheimer's disease," CNS and Neurological Disorders-Drug Targets, vol. 8, no. 1, pp. 16-30, 2009.

[48] P. Lewczuk, J. Kornhuber, E. Vanmechelen et al., "Amyloid $\beta$ peptides in plasma in early diagnosis of Alzheimer's disease: a multicenter study with multiplexing," Experimental Neurology, vol. 223, no. 2, pp. 366-370, 2010.

[49] N. R. Graff-Radford, J. E. Crook, J. Lucas et al., "Association of low plasma $A \beta 42 / A \beta 40$ ratios with increased imminent risk for mild cognitive impairment and Alzheimer disease," Archives of Neurology, vol. 64, no. 3, pp. 354-362, 2007. 
[50] M. van Oijen, A. Hofman, H. D. Soares, P. J. Koudstaal, and M. M. Breteler, "Plasma A $\beta 1-40$ and $A \beta 1-42$ and the risk of dementia: a prospective case-cohort study," Lancet Neurology, vol. 5, no. 8, pp. 655-660, 2006.

[51] L. Wang-Dietrich, S. A. Funke, K. Kühbach et al., "The amyloid$\beta$ oligomer count in cerebrospinal fluid is a biomarker for Alzheimer's disease," Journal of Alzheimer's Disease, vol. 34, no. 4, pp. 985-994, 2013.

[52] F. Hulstaert, K. Blennow, A. Ivanoiu et al., "Improved discrimination of AD patients using $\beta$-amyloid((1-42)) and tau levels in CSF," Neurology, vol. 52, no. 8, pp. 1555-1562, 1999.

[53] D. Galasko, L. Chang, R. Motter et al., "High cerebrospinal fluid tau and low amyloid $\beta 42$ levels in the clinical diagnosis of Alzheimer disease and relation to apolipoprotein E genotype," Archives of Neurology, vol. 55, no. 7, pp. 937-945, 1998.

[54] L. Buée, T. Bussière, V. Buée-Scherrer, A. Delacourte, and P. R. Hof, "Tau protein isoforms, phosphorylation and role in neurodegenerative disorders," Brain Research Reviews, vol. 33, no. 1, pp. 95-130, 2000.

[55] E. Mandelkow, M. Von Bergen, J. Biernat, and E. Mandelkow, "Structural principles of tau and the paired helical filaments of Alzheimer's disease," Brain Pathology, vol. 17, no. 1, pp. 83-90, 2007.

[56] N. J. Cairns, V. M.-Y. Lee, and J. Q. Trojanowski, “The cytoskeleton in neurodegenerative diseases," Journal of Pathology, vol. 204, no. 4, pp. 438-449, 2004.

[57] N. Shahani and R. Brandt, "Functions and malfunctions of the tau proteins," Cellular and Molecular Life Sciences, vol. 59, no. 10, pp. 1668-1680, 2002.

[58] I. Morales, J. M. Jimenez, M. Mancilla, and R. B. Maccioni, "Tau oligomers and fibrils induce activation of microglial cells," Journal of Alzheimer's Disease, vol. 37, no. 4, pp. 849-856, 2013.

[59] A. Takashima, "Tauopathies and tau oligomers," Journal of Alzheimer's Disease, vol. 37, no. 3, pp. 565-568, 2013.

[60] M. Mawal-Dewan, J. Henley, A. Van De Voorde, J. Q. Trojanowski, and V. M.-Y. Lee, "The phosphorylation state of tau in the developing rat brain is regulated by phosphoprotein phosphatases," Journal of Biological Chemistry, vol. 269, no. 49, pp. 30981-30987, 1994.

[61] H. Rosner, M. Rebhan, G. Vacun, and E. Vanmechelen, "Developmental expression of tau proteins in the chicken and rat brain: rapid down-regulation of a paired helical filament epitope in the rat cerebral cortex coincides with the transition from immature to adult tau isoforms," International Journal of Developmental Neuroscience, vol. 13, no. 6, pp. 607-617, 1995.

[62] T. Sunderland, G. Linker, N. Mirza et al., "Decreased $\beta$ Amyloid1-42 and Increased Tau Levels in Cerebrospinal Fluid of Patients with Alzheimer Disease," Journal of the American Medical Association, vol. 289, no. 16, pp. 2094-2103, 2003.

[63] C. Hesse, L. Rosengren, N. Andreasen et al., "Transient increase in total tau but not phospho-tau in human cerebrospinal fluid after acute stroke," Neuroscience Letters, vol. 297, no. 3, pp. 187190, 2001.

[64] M. Otto, J. Wiltfang, H. Tumani et al., "Elevated levels of tauprotein in cerebrospinal fluid of patients with Creutzfeldt-Jakob disease," Neuroscience Letters, vol. 225, no. 3, pp. 210-212, 1997.

[65] K. Iqbal, I. Grundke-Iqbal, T. Zaidi et al., "Defective brain microtubule assembly in Alzheimer's disease," The Lancet, vol. 2, no. 8504, pp. 421-426, 1986.

[66] I. Grundke-Iqbal, K. Iqbal, and Y.-C. Tung, "Abnormal phosphorylation of the microtubule-associated protein $\tau$ (tau) in
Alzheimer cytoskeletal pathology," Proceedings of the National Academy of Sciences of the United States of America, vol. 83, no. 13, pp. 44913-4917, 1986.

[67] K. Blennow, E. Vanmechelen, and H. Hampel, "CSF total tau, $\mathrm{A} \beta 42$ and phosphorylated tau protein as biomarkers for Alzheimer's disease," Molecular Neurobiology, vol. 24, no. 1-3, pp. 87-97, 2001.

[68] P. Lewczuk, H. Esselmann, M. Bibl et al., “Tau protein phosphorylated at threonine 181 in CSF as a neurochemical biomarker in Alzheimer's disease: original data and review of the literature," Journal of Molecular Neuroscience, vol. 23, no. 1-2, pp. 115-122, 2004.

[69] E. Vanmechelen, E. Van Kerschaver, K. Blennow et al., "CSFPhospho-tau (181P) as a Promising Marker for Discriminating Alzheimer's Disease from Dementia with Lewy Bodies," in Alzheimer's Disease: Advances in Etiology, Pathogenesis and Therapeutics, K. Iqbal, S. S. Sisodia, and B. Winblad, Eds., pp. 285-291, John Wiley and Sons, Chichester, UK, 2001.

[70] L. Parnetti, A. Lanari, S. Amici, V. Gallai, E. Vanmechelen, and F. Hulstaert, "CSF phosphorylated tau is a possible marker for discriminating Alzheimer's disease from dementia with Lewy bodies," Neurological Sciences, vol. 22, no. 1, pp. 77-78, 2001.

[71] N. Itoh, H. Arai, K. Urakami et al., "Large-scale, multicenter study of cerebrospinal fluid tau protein phosphorylated at serine 199 for the antemortem diagnosis of Alzheimer's disease," Annals of Neurology, vol. 50, no. 2, pp. 150-156, 2001.

[72] H. Hampel, K. Buerger, R. Kohnken et al., "Tracking of Alzheimer's disease progression with cerebrospinal fluid tau protein phosphorylated at threonine 231," Annals of Neurology, vol. 49, no. 4, pp. 545-546, 2001.

[73] H. Arai, K. Ishiguro, H. Ohno et al., "CSF phosphorylated tau protein and mild cognitive impairment: a prospective study," Experimental Neurology, vol. 166, no. 1, pp. 201-203, 2000.

[74] Z. F. Wang, H. L. Li, X. C. Li et al., "Effects of endogenous $\beta$ amyloid overproduction on tau phosphorylation in cell culture," Journal of Neurochemistry, vol. 98, no. 4, pp. 1167-1175, 2006.

[75] F. Grueninger, B. Bohrmann, C. Czech et al., "Phosphorylation of Tau at $\mathrm{S} 422$ is enhanced by $\mathrm{A} \beta$ in TauPS2APP triple transgenic mice," Neurobiology of Disease, vol. 37, no. 2, pp. 294$306,2010$.

[76] H. C. Huang and Z. F. Jiang, "Accumulated amyloid- $\beta$ peptide and hyperphosphorylated tau protein: relationship and links in Alzheimer's disease," Journal of Alzheimer's Disease, vol. 16, no. 1, pp. 15-27, 2009.

[77] A. Mudher and S. Lovestone, "Alzheimer's disease-do tauists and baptists finally shake hands?" Trends in Neurosciences, vol. 25, no. 1, pp. 22-26, 2002.

[78] P. Lewczuk, R. Zimmermann, J. Wiltfang, and J. Kornhuber, "Neurochemical dementia diagnostics: a simple algorithm for interpretation of the CSF biomarkers," Journal of Neural Transmission, vol. 116, no. 9, pp. 1163-1167, 2009.

[79] S. Slaets, N. Le Bastard, J. Martin et al., “Cerebrospinal fluid A $\beta 1$ 40 improves differential dementia diagnosis in patients with intermediate P-tau181P levels," Journal of Alzheimer's Disease, vol. 36, no. 4, pp. 759-767, 2013.

[80] M. S. Albert, S. T. DeKosky, D. Dickson et al., "The diagnosis of mild cognitive impairment due to Alzheimer's disease: recommendations from the National Institute on AgingAlzheimer's Association workgroups on diagnostic guidelines for Alzheimer's disease," Alzheimer's and Dementia, vol. 7, no. 3, pp. 270-279, 2011. 
[81] C. R. Jack Jr., M. S. Albert, D. S. Knopman et al., "Introduction to the recommendations from the National Institute on AgingAlzheimer's Association workgroups on diagnostic guidelines for Alzheimer's disease," Alzheimer's and Dementia, vol. 7, no. 3, pp. 257-262, 2011.

[82] G. M. McKhann, "Changing concepts of Alzheimer disease," Journal of the American Medical Association, vol. 305, no. 23, pp. 2458-2459, 2011.

[83] R. A. Sperling, P. S. Aisen, L. A. Beckett et al., "Toward defining the preclinical stages of Alzheimer's disease: recommendations from the National Institute on Aging-Alzheimer's Association workgroups on diagnostic guidelines for Alzheimer's disease," Alzheimer's and Dementia, vol. 7, no. 3, pp. 280-292, 2011.

[84] S3-Leitlinie, "Demenzen", 2009 http://www.dggpp.de/documents/s3-leitlinie-demenz-kf.pdf.

[85] J. C. Morris, K. Blennow, L. Froelich et al., "Harmonized diagnostic criteria for Alzheimer's disease: recommendations," Journal of Internal Medicine, vol. 275, no. 3, pp. 204-213, 2014.

[86] G. M. McKhann, D. S. Knopman, H. Chertkow et al., “The diagnosis of dementia due to Alzheimer's disease: recommendations from the National Institute on Aging-Alzheimer's Association workgroups on diagnostic guidelines for Alzheimer's disease," Alzheimer's and Dementia, vol. 7, no. 3, pp. 263-269, 2011.

[87] O. Hansson, H. Zetterberg, P. Buchhave, E. Londos, K. Blennow, and L. Minthon, "Association between CSF biomarkers and incipient Alzheimer's disease in patients with mild cognitive impairment: a follow-up study," Lancet Neurology, vol. 5, no. 3, pp. 228-234, 2006.

[88] N. Mattsson, H. Zetterberg, O. Hansson et al., "CSF biomarkers and incipient Alzheimer disease in patients with mild cognitive impairment," Journal of the American Medical Association, vol. 302, no. 4, pp. 385-393, 2009.

[89] H. Zetterberg, L. Wahlund, and K. Blennow, "Cerebrospinal fluid markers for prediction of Alzheimer's disease," Neuroscience Letters, vol. 352, no. 1, pp. 67-69, 2003.

[90] P. Lewczuk, J. Kornhuber, H. Vanderstichele et al., "Multiplexed quantification of dementia biomarkers in the CSF of patients with early dementias and MCI: a multicenter study," Neurobiology of Aging, vol. 29, no. 6, pp. 812-818, 2008.

[91] I. A. van Rossum, S. Vos, R. Handels, and P. J. Visser, "Biomarkers as predictors for conversion from mild cognitive impairment to Alzheimer-type dementia: implications for trial design," Journal of Alzheimer's Disease, vol. 20, no. 3, pp. 881-891, 2010.

[92] C. R. Jack Jr., D. S. Knopman, W. J. Jagust et al., "Hypothetical model of dynamic biomarkers of the Alzheimer's pathological cascade," The Lancet Neurology, vol. 9, no. 1, pp. 119-128, 2010.

[93] D. S. Knopman, J. E. Parisi, A. Salviati et al., "Neuropathology of cognitively normal elderly," Journal of Neuropathology and Experimental Neurology, vol. 62, no. 11, pp. 1087-1095, 2003.

[94] C. Ballatore, V. M.-Y. Lee, and J. Q. Trojanowski, “Tau-mediated neurodegeneration in Alzheimer's disease and related disorders," Nature Reviews Neuroscience, vol. 8, no. 9, pp. 663-672, 2007.

[95] P. Vemuri, H. J. Wiste, S. D. Weigand et al., "MRI and CSF biomarkers in normal, $\mathrm{MCI}$, and $\mathrm{AD}$ subjects: diagnostic discrimination and cognitive correlations," Neurology, vol. 73, no. 4, pp. 287-293, 2009.
[96] E. S. Musiek and D. M. Holtzman, “Origins of Alzheimer's disease: reconciling cerebrospinal fluid biomarker and neuropathology data regarding the temporal sequence of amyloidbeta and tau involvement," Current Opinion in Neurology, vol. 25, no. 6, pp. 715-720, 2012.

[97] H. Struyfs, J. L. Molinuevo, J. J. Martin, P. P. De Deyn, and S. Engelborghs, "Validation of the AD-CSF-index in autopsyconfirmed Alzheimer's disease patients and healthy controls," Journal of Alzheimer's Disease, 2014.

[98] P. Scheltens and K. Rockwood, "How golden is the gold standard of neuropathology in dementia?" Alzheimer's and Dementia, vol. 7, no. 4, pp. 486-489, 2011.

[99] R. Zimmermann, E. Huber, C. Schamber et al., "Plasma concentrations of the amyloid- $\beta$ peptides in young volunteers: the influence of the APOE genotype," Journal of Alzheimer's Disease, vol. 40, no. 4, pp. 1055-1060, 2014.

[100] J. Popp, P. Lewczuk, I. Frommann et al., "Cerebrospinal fluid markers for alzheimer's disease over the lifespan: effects of age and the APOE\&4 genotype," Journal of Alzheimer's Disease, vol. 22, no. 2, pp. 459-468, 2010.

[101] W. Khan, V. Giampietro, C. Ginestet et al., "No differences in hippocampal volume between carriers and non-carriers of the ApoE epsilon4 and epsilon2 alleles in young healthy adolescents," Journal of Alzheimer's Disease, vol. 40, no. 1, pp. 37-43, 2014.

[102] R. J. Bateman, C. Xiong, T. L. S. Benzinger et al., "Clinical and biomarker changes in dominantly inherited Alzheimer's disease," New England Journal of Medicine, vol. 367, no. 9, pp. 795-804, 2012.

[103] K. A. Johnson, N. C. Fox, R. A. Sperling, and W. E. Klunk, "Brain imaging in Alzheimer disease," Cold Spring Harbor Perspectives in Medicine, vol. 2, no. 4, Article ID a006213, 2012.

[104] L. Mosconi, H. T. Wai, A. Pupi et al., "18F-FDG PET database of longitudinally confirmed healthy elderly individuals improves detection of mild cognitive impairment and Alzheimer's disease," Journal of Nuclear Medicine, vol. 48, no. 7, pp. 1129-1134, 2007.

[105] V. Kepe, M. C. Moghbel, B. Långströmd et al., "Amyloid$\beta$ positron emission tomography imaging probes: a critical review," Journal of Alzheimer's Disease, vol. 36, no. 4, pp. 613631, 2013.

[106] S. Vos, I. van Rossum, L. Burns et al., "Test sequence of CSF and MRI biomarkers for prediction of AD in subjects with MCI," Neurobiology of Aging, vol. 33, no. 10, pp. 2272-2281, 2012.

[107] M. Brys, L. Glodzik, L. Mosconi et al., "Magnetic resonance imaging improves cerebrospinal fluid biomarkers in the early detection of Alzheimer's disease," Journal of Alzheimer's Disease, vol. 16, no. 2, pp. 351-362, 2009.

[108] N. S. M. Schoonenboom, C. Mulder, H. Vanderstichele et al., "Effects of processing and storage conditions on amyloid $\beta$ (142) and tau concentrations in cerebrospinal fluid: implications for use in clinical practice," Clinical Chemistry, vol. 51, no. 1, pp. 189-195, 2005.

[109] M. Jensen, T. Hartmann, B. Engvall et al., "Quantification of Alzheimer amyloid beta peptides ending at residues 40 and 42 by novel ELISA systems," Molecular Medicine, vol. 6, no. 4, pp. 291-302, 2000.

[110] H. Vanderstichele, E. Van Kerschaver, C. Hesse et al., "Standardization of measurement of $\beta$-amyloid((1-42)) in cerebrospinal fluid and plasma," Amyloid, vol. 7, no. 4, pp. 245-258, 2000.

[111] H. Vanderstichele, M. Bibl, S. Engelborghs et al., "Standardization of preanalytical aspects of cerebrospinal fluid biomarker 
testing for Alzheimer's disease diagnosis: a consensus paper from the Alzheimer's Biomarkers Standardization Initiative," Alzheimer's and Dementia, vol. 8, no. 1, pp. 65-73, 2012.

[112] R. J. Bateman, E. R. Siemers, K. G. Mawuenyega et al., "A $\gamma$-secretase inhibitor decreases amyloid- $\beta$ production in the central nervous system," Annals of Neurology, vol. 66, no. 1, pp. 48-54, 2009.

[113] M. Bjerke, E. Portelius, L. Minthon et al., "Confounding factors influencing amyloid beta concentration in cerebrospinal fluid," International Journal of Alzheimer's Disease, Article ID 986310, 2010.

[114] A. Perret-Liaudet, M. Pelpel, S. Lehmann, S. Schraen, H. Vanderstichele, and I. Quadrio, "Sampling tube, a critical factor in Alzheimer disease biomarker standardization," in Proceedings of the International Conference on Alzheimer's Disease, Honolulu, Hawaii, USA, July 2010.

[115] R. Zimmermann, N. Lelental, O. Ganslandt, J. M. Maler, J. Kornhuber, and P. Lewczuk, "Preanalytical sample handling and sample stability testing for the neurochemical dementia diagnostics," Journal of Alzheimer's Disease, vol. 25, no. 4, pp. 739-745, 2011.

[116] "Richtlinie der Bundesärztekammer zur qulitätssicherung laboratoriumsmedizinischen Untersuchungen," Deutsches Ärzteblatt, vol. 105, pp. A341-A355, 2008.

[117] J. Waedt, M. Kleinow, J. Kornhuber, and P. Lewczuk, "Neurochemical dementia diagnostics for Alzheimers disease and other dementias: an ISO 15189 perspective," Biomarkers in Medicine, vol. 6, no. 5, pp. 685-690, 2012.

[118] N. A. Verwey, W. M. Van Der Flier, K. Blennow et al., "A worldwide multicentre comparison of assays for cerebrospinal fluid biomarkers in Alzheimer's disease," Annals of Clinical Biochemistry, vol. 46, no. 3, pp. 235-240, 2009.

[119] M. C. Carrillo, K. Blennow, H. Soares et al., "Global standardization measurement of cerebral spinal fluid for Alzheimer's disease: an update from the Alzheimer's Association Global Biomarkers Consortium," Alzheimer's and Dementia, vol. 9, no. 2, pp. 137-140, 2013.

[120] N. Mattsson, U. Andreasson, S. Persson et al., "The Alzheimer's Association external quality control program for cerebrospinal fluid biomarkers," Alzheimer's and Dementia, vol. 7, no. 4, pp. 386.e6-395.e6, 2011.

[121] Consensus report of the Working Group, "Molecular and biochemical markers of Alzheimer's disease," Neurobiology of Aging, vol. 19, no. 2, pp. 109-116, 1998.

[122] EMA, Qualification Opinion of Alzheimer's Disease Novel Methodologies/biomarkers for BMS-708163, 2011.

[123] J. Randall, E. Mörtberg, G. K. Provuncher et al., "Tau proteins in serum predict neurological outcome after hypoxic brain injury from cardiac arrest: results of a pilot study," Resuscitation, vol. 84, no. 3, pp. 351-356, 2013.

[124] H. Reiber, "Dynamics of brain-derived proteins in cerebrospinal fluid," Clinica Chimica Acta, vol. 310, no. 2, pp. 173186, 2001.

[125] K. Felgenhauer and W. Beuche, Labordiagnostik Neurologischer Erkrankungen: Liquoranalytik und -Zytologie, Diagnose- und Processmarker, Thieme, Stuttgart, Germany, 1999.

[126] R. B. DeMattos, K. R. Bales, D. J. Cummins, J. Dodart, S. M. Paul, and D. M. Holtzman, "Peripheral anti-A $\beta$ antibody alters $\mathrm{CNS}$ and plasma $\mathrm{A} \beta$ clearance and decreases brain $\mathrm{A} \beta$ burden in a mouse model of Alzheimer's disease," Proceedings of the National Academy of Sciences of the United States of America, vol. 98 , no. 15, pp. 8850-8855, 2001.
[127] R. B. DeMattos, K. R. Bales, D. J. Cummins, S. M. Paul, and D. M. Holtzman, "Brain to plasma amyloid- $\beta$ efflux: a measure of brain amyloid burden in a mouse model of Alzheimer's disease," Science, vol. 295, no. 5563, pp. 2264-2267, 2002.

[128] S. D. Preston, P. V. Steart, A. Wilkinson, J. A. R. Nicoll, and R. O. Weller, "Capillary and arterial cerebral amyloid angiopathy in Alzheimer's disease: defining the perivascular route for the elimination of amyloid $\beta$ from the human brain," Neuropathology and Applied Neurobiology, vol. 29, no. 2, pp. 106-117, 2003.

[129] M. Di Luca, L. Pastorino, A. Bianchetti et al., "Differential level of platelet amyloid $\beta$ precursor protein isoforms: an early marker for Alzheimer disease," Archives of Neurology, vol. 55, no. 9, pp. 1195-1200, 1998.

[130] Y.-M. Kuo, T. A. Kokjohn, M. D. Watson et al., "Elevated A $\beta 42$ in skeletal muscle of Alzheimer disease patients suggests peripheral alterations of A $\beta \mathrm{PP}$ metabolism," American Journal of Pathology, vol. 156, no. 3, pp. 797-805, 2000.

[131] P. Lewczuk, H. Esselmann, M. Bibl et al., "Electrophoretic separation of amyloid $\beta$ peptides in plasma," Electrophoresis, vol. 25, no. 20, pp. 3336-3343, 2004.

[132] J. M. Maler, H. Klafki, S. Paul et al., "Urea-based twodimensional electrophoresis of beta-amyloid peptides in human plasma: evidence for novel A $\beta$ species," Proteomics, vol. 7, no. 20, pp. 3815-3820, 2007.

[133] R. Mayeux, L. S. Honig, M.-X. Tang et al., "Plasma A40 and A42 and Alzheimer's disease: relation to age, mortality, and risk," Neurology, vol. 61, no. 9, pp. 1185-1190, 2003.

[134] S. H. Freeman, S. Raju, B. T. Hyman, M. P. Frosch, and M. C. Irizarry, "Plasma A $\beta$ levels do not reflect brain A $\beta$ levels," Journal of Neuropathology and Experimental Neurology, vol. 66, no. 4, pp. 264-271, 2007.

[135] V. Giedraitis, J. Sundelöf, M. C. Irizarry et al., "The normal equilibrium between CSF and plasma amyloid beta levels is disrupted in Alzheimer's disease," Neuroscience Letters, vol. 427, no. 3, pp. 127-131, 2007.

[136] X. Sun, D. C. Steffens, R. Au et al., "Amyloid-associated depression: a prodromal depression of Alzheimer disease?" Archives of General Psychiatry, vol. 65, no. 5, pp. 542-550, 2008.

[137] R. L. Ownby, E. Crocco, A. Acevedo, V. John, and D. Loewenstein, "Depression and risk for Alzheimer disease: systematic review, meta-analysis, and metaregression analysis," Archives of General Psychiatry, vol. 63, no. 5, pp. 530-538, 2006.

[138] O. Hansson, H. Zetterberg, E. Vanmechelen et al., "Evaluation of plasma $\mathrm{A} \beta 40$ and $\mathrm{A} \beta 42$ as predictors of conversion to Alzheimer's disease in patients with mild cognitive impairment," Neurobiology of Aging, vol. 31, no. 3, pp. 357-367, 2010.

[139] A. Koyama, O. I. Okereke, T. Yang, D. Blacker, D. J. Selkoe, and F. Grodstein, "Plasma amyloid- $\beta$ as a predictor of dementia and cognitive decline: a systematic review and meta-analysis," Archives of Neurology, vol. 69, no. 7, pp. 824-831, 2012.

[140] A. D. Watt, K. A. Perez, A. R. Rembach, C. L. Masters, V. L. Villemagne, and K. J. Barnham, "Variability in blood-based amyloid- $\beta$ assays: the need for consensus on pre-analytical processing," Journal of Alzheimer's Disease, vol. 30, no. 2, pp. 323-336, 2012. 


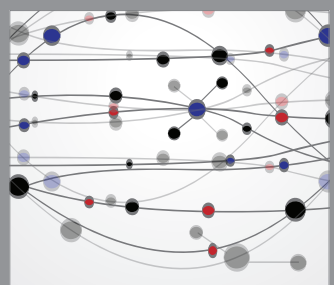

The Scientific World Journal
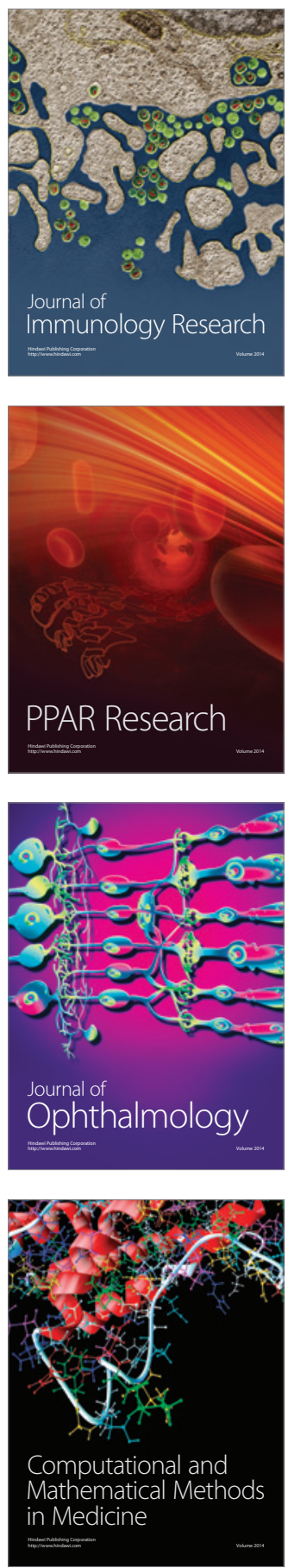

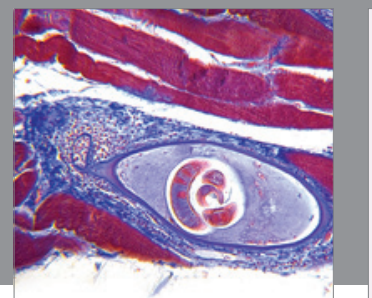

Gastroenterology

Research and Practice
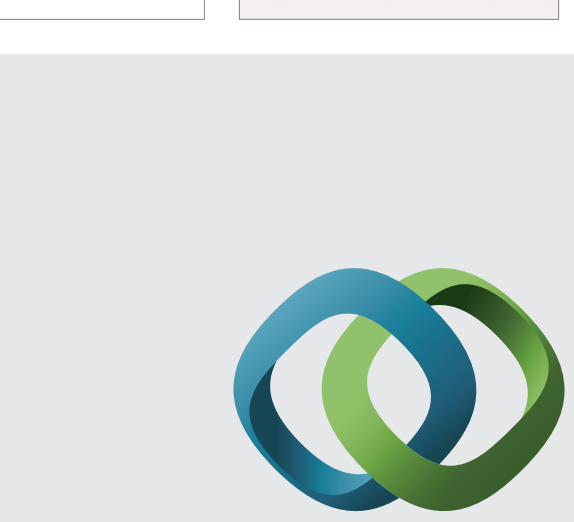

\section{Hindawi}

Submit your manuscripts at

http://www.hindawi.com
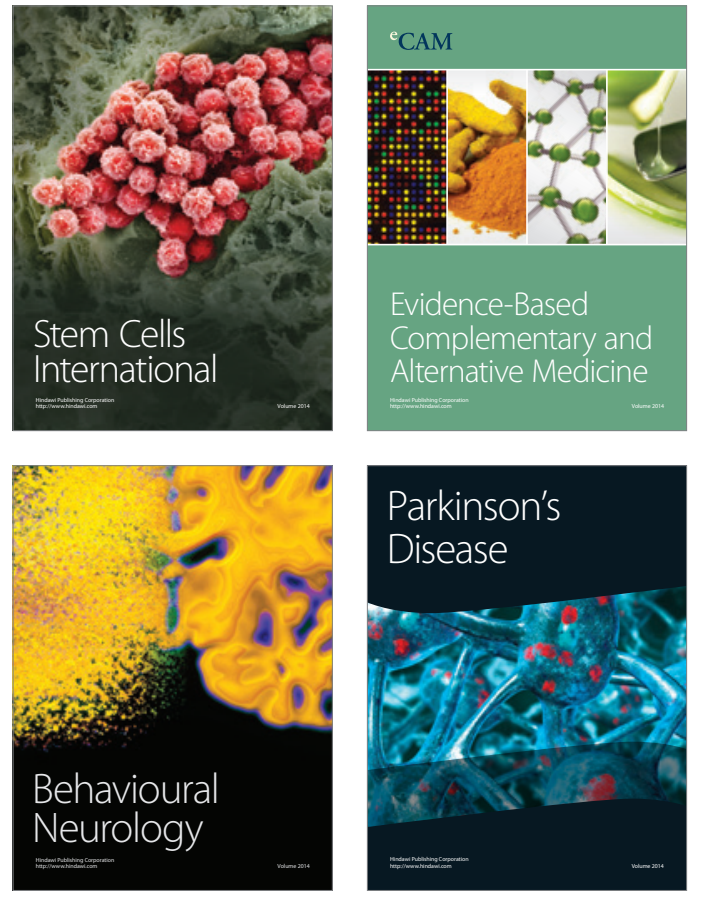
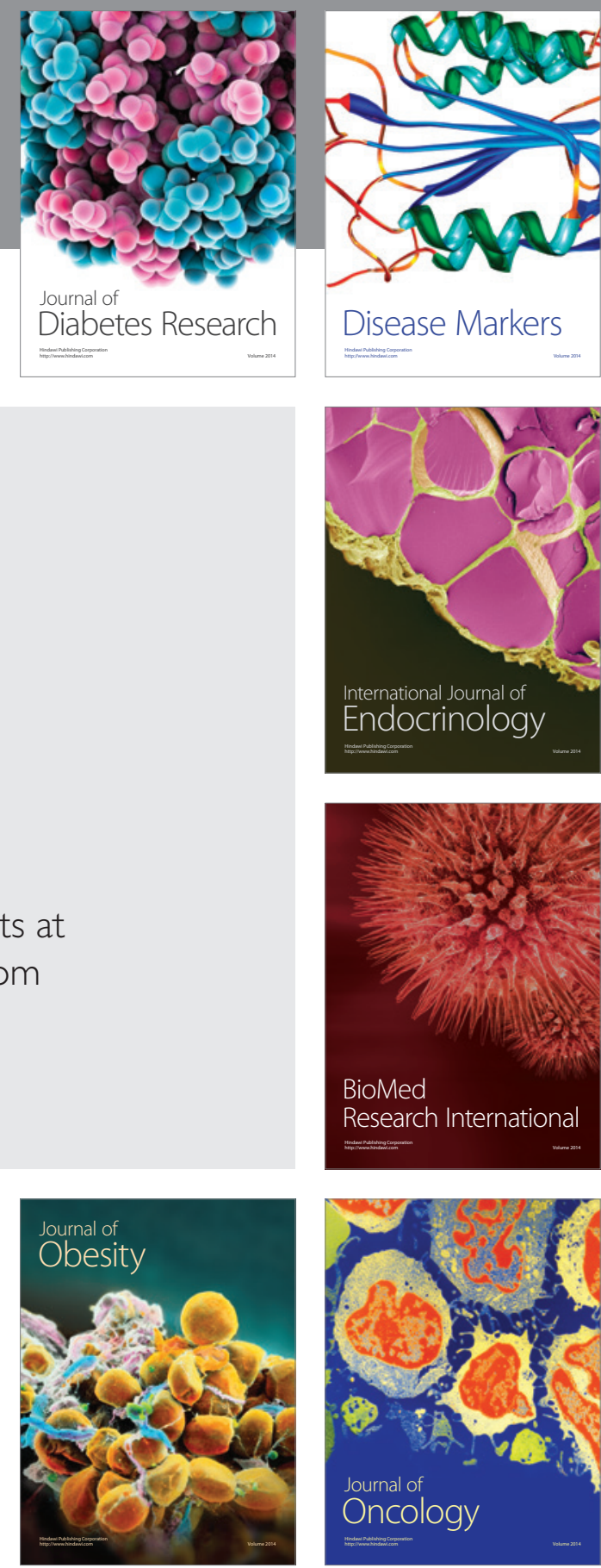

Disease Markers
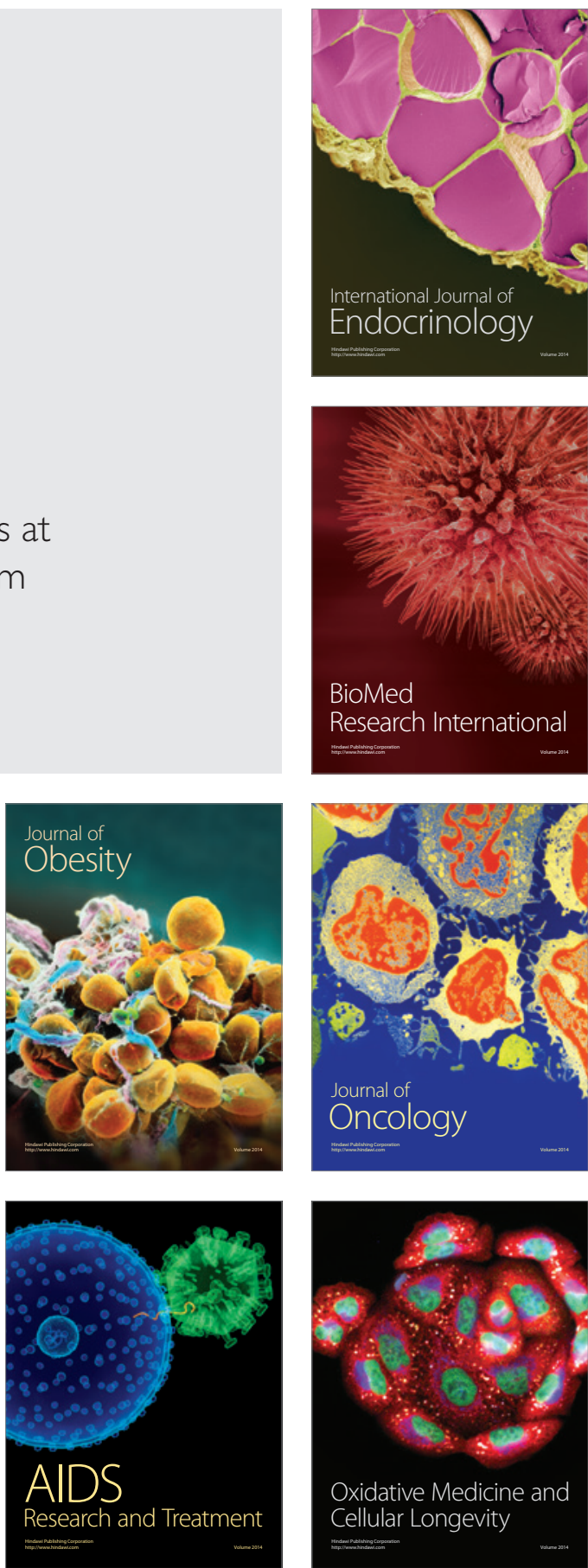